\title{
SAFETY OF CARBON FIBRE REINFORCED PLASTIC HOLLOW SECTIONS IN COMPRESSION
}

\author{
O. S. Abejide ${ }^{1}$ and E. E. Okoro ${ }^{2, *}$ \\ 1 Department of Civil Engineering, Ahmadu Bello University, Zaria. Kaduna State. NigERIA, \\ 2 Department of Civil EngineEring, WaZiri Umaru Federal Polytechnic, Birnin KebBi, Kebbi State. NiGeria. \\ Email addresses:1 abejideos@yahoo.com,2emmadinma90@yahoo.com
}

\begin{abstract}
The use of steel hollow sections as compression members in structures has been a common practice. This study highlights the safety of using Carbon Fibre Reinforced Plastic (CFRP) hollow sections as compression structural members. The primary compression members in structures are columns and this study uses Finite Element Analysis (FEA) to investigate the effects of pure axial compressive loads on CFRP hollow sections. Hollow CFRP columns having different sizes and material thicknesses were modeled using ABAQUS/CAE three-dimensional nonlinear finite element analysis and the results obtained are used to measure the deformation under compression. All loads used were Euler's critical buckling load. Steel hollow sections were also designed using the same method. This serves as a basis of comparison for a number of factors such as material thickness, section shape, deformation scale factor, size of cavity and length effect that will ultimately affect the deformation and failure of columns under axial compressive loads. Results show that at critical axial loads there is no considerable buckling at mid-height for CFRP hollow sections and steel hollow sections. Analysis of results from ABAQUS/CAE concluded that for most cases under critical loading, CFRP hollow sections shorten in length and increase in lateral dimension; this explains the growing trend of using CFRP hollow sections as confinement for reinforced concrete columns, given that concrete is good in compression. For axial compressive loads less than the critical loads, CFRP hollow sections are generally safe.
\end{abstract}

Keywords: structural safety, cfrp, hollow section, compression.

\section{INTRODUCTION}

\subsection{General}

For years now, civil engineers have been in search for alternatives to steel and alloys to combat the high costs of repair and maintenance of structures damaged by corrosion and heavy use. Fibre reinforced polymer (FRP) is a relatively new class of composite material manufactured from fibres and resins and has proven efficient and economical for the development and repair of new and deteriorating structures in civil engineering. The mechanical properties of FRPs make them ideal for widespread applications in construction worldwide.

Fibre-reinforced polymer (FRP) composites are increasingly being used in civil infrastructure in applications ranging from reinforcing rods and tendons, wraps for seismic retrofit of columns, and externally bonded reinforcement for strengthening of walls, beams, slabs, composite bridge decks, and composite structural systems. Their use in this application is predicated on performance attributes linked to their light weight, high stiffness-to-weight and strength-to-weight ratios, ease of installation in the field, potential lower systems level cost, and potentially high overall durability. In general, civil structures are expected to have long service lives and are not inspected at the same level as aerospace structures. Since FRP composites are still relatively unknown to the practicing civil engineer and infrastructure systems planner, there are heightened concerns related to the overall durability of these materials, especially as related to their capacity for sustained performance under harsh and changing environmental conditions under load. The primary obstacle that hinders the wide application of FRP composites in civil infrastructures is the long-term 
durability performance, especially when the structure is undergoing combined harsh environmental conditions. Even though the FRP system has been used in aerospace engineering for almost a century and demonstrated good durability characteristics, those FRP possesses much better quality than the one currently used in civil infrastructures and its excellent durability performance cannot be directly applied to the civil engineering case. This is why many researchers did a lot of work and study during the past few decades to investigate the durability of this new material in civil engineering applications [1].

This paper investigates the compressive performances of CFRP hollow sections and modes of failure of reinforced concrete structural elements after strengthening with externally bonded carbon fibrereinforced plastic (CFRP) tubes, and the effectiveness of using externally bonded CFRP strips in repairs of reinforced concrete structural elements. Over the years researchers have mainly focused their attention on solid columns. Few studies to date have covered circular and rectangular hollow columns. The performance of cross sections of columns subjected to combined shear and flexure stresses was experimentally investigated by [2]. The stress-strain behaviour of hollow FRP-confined concrete columns under compressive loads was studied by [3]. These researches gave useful information regarding the behaviour of hollow concrete columns confined with FRP under monotonic compression, with respect to concrete strength, aspect ratio, shape of the cross section and type of FRP material.

CFRP has recently become somewhat of a hot topic in the field of structural engineering, surprisingly enough, due to cost-effectiveness. For examples, many old bridges in the world were designed to tolerate far lower service loads than they are subjected to today, and compared with the cost of replacing the bridges, reinforcing them with CFRP is quite cheap. Due to the incredible stiffness of CFRP, it can be used underneath spans to help prevent excessive deflections, or wrapped around beams to limit shear stresses. Much research is also now being done using CFRP as internal reinforcement in concrete structures, such as beams and bridge decks. The material has many advantages over conventional steel; mainly that it is much stiffer and corrosion resistant. There is, however, some hesitation among the engineering community about using these new materials until more real life evaluations have been done.
A number of researchers have demonstrated that carbon fibre reinforced polymer (CFRP) materials can be used to strengthen steel compression members [46]. In one early study a conventional modulus CFRP system was developed by considering a number of factors including material selection, system behaviour under static and fatigue loads, environmental durability and basic bond characteristics $[7,8,9]$. However, the research did not provide guidelines to facilitate the design and implementation of the system for field application. Most early researches focused on the use of conventional CFRP materials with a modulus of elasticity typically equal to or less than that of steel. Thus, although the materials could effectively enhance the strength of the structure, large amounts of strengthening materials were required to improve the serviceability. Recent research has also focused on the bond characteristics of CFRP materials bonded to steel surfaces [10]. A number of analytical models have been developed to describe the bond behaviour [11-14]. Other researches, primarily in the mechanical, aerospace and marine industries, have demonstrated that bond strength is highly affected by the shape of the end of the strengthening plate. Research on the environmental durability of CFRP-tosteel bond is limited, particularly in the civil engineering and infrastructure disciplines. In strengthening systems, the CFRP materials typically have excellent resistance against environmental conditions [15]; however, the performance of adhesive between CFRP and steel/concrete may be affected by various environmental conditions [16].

CFRP hollows can also be applied to enhance shear strength of reinforced concrete by wrapping fabrics or fibres around the section to be strengthened. The behaviour of circular hollow section short columns strengthened with FRP composites under compression was investigated experimentally by [17] and they observed that the use of CFRP confinement greatly enhances the load carrying capacity of circular steel tubes. Wrapping around sections (such as bridge or building columns) can also enhance the ductility of the section, greatly increasing the resistance to collapse under earthquake loading. In this paper the safety of carbon fibre reinforced plastic hollow sections in compression is investigated. Hollow CFRP columns having different sizes and material thicknesses are modeled using ABAQUS/CAE finite element. 


\subsection{Axially Loaded Circular CFRP Tubes (Concrete Filled)}

There is a great demand for columns, beams and piles to be constructed using more durable materials in comparison to traditional construction materials. Concrete-filled steel tubes are widely used as bridge columns in Japan, China, and Europe to not only accelerate construction but also to obtain superior seismic performance [1]. FRP tubes have gained acceptance as an alternative to steel tubes in concretefilled steel tubes. Concrete-filled fiber tubes have benefits that are similar to those of concrete-filled steel tubes. However, unlike steel tubes, FRP tubes have a lighter weight-to-strength ratio and a higher corrosion resistance than steel tubes have.

For practical applications, CFRP tubes are used to carry axial compression loads and may also be designed to resist bending moments. Most of the reported experimental and analytical researches in the area of concrete confinement using CFRP [18] included CFRP tubes totally filled with concrete and the fibres were mainly oriented in the hoop direction to provide maximum stiffness and strength for confinement. Other studies considered the case of applying the axial load to the concrete core only for an optimum use of the CFRP tube in the hoop direction for confinement [19]. In such a case, slip could take place between the concrete and the outer tube, and consequently the member cannot resist bending. Confinement of concrete cylinders wrapped with CFRP sheets and subjected to axial loading conditions was also studied by other researchers [20,21].

In the design of civil engineering structures, various codes simplify design and proffer code requirements and guidelines for design of structural elements, taking account of reinforcing steel, concrete and the confining material itself. Other codes such as [22] also proffer similar equations to obtain axial loads on confined concrete sections. The design equation for evaluation of compressive load capacity in concretefilled steel tube columns provided in the Canadian Steel Code, [23] is modified and utilized in design of columns. The unfactored compressive load capacity of the column is expressed as:

$$
P_{u}=P_{c s}\left(1+\lambda^{2 n}\right)^{-1 / n}
$$

where: $P_{u}=$ Unfactored axial load capacity

$P_{c s}=$ Cross-section compressive load capacity

$$
\lambda=\sqrt{P_{c s} / P_{E}}
$$

$P_{E}=$ Euler's buckling load

$n=0.97$, a coefficient derived by regression analysis using the capacity curve developed from the strain softening of the composite columns. For the purpose of this study, Euler's buckling load will be considered to be an estimate for the axial compressive load where there is no analytic model and no test was carried out. All components of the composite columns are taken into account.

\section{LIMIT STATE FUNCTIONS AND PERFORMANCE EQUATIONS}

Considering previous experiments on concrete-filled CFRP laminates subjected to pure axial load it is necessary to present a set of equations on the functionality and performance of concrete and even the CFRP tube itself as a basis for evaluating safety. For most reinforced concrete structures it is usual to commence the design for the condition at ultimate limit state, followed by checks to ensure that the structure is adequate for serviceability limit state without excessive deflection or cracking, flexure or bending, shear or cut and other forms of failure when subjected to axial compressive loads [24]. For compressive loads, deflection, shear and flexure are the most practical causes of failure. Limit state equations that proffer specific recommendation to meet up with safety standards are provided by [25]. Assessment of the state of a structural element has been either failed or safe. It is obtained from the traditional deterministic analysis, but certain input parameters are identified and quantified. Interpretation of what is considered to be an acceptable failure probability is made with the consideration of the sequence of failure which is predetermined.

The limit state is a function of material properties, loads and dimensions which is expressed as:

$g(x)=R-S$

The state of performance function $\mathrm{g}(\mathrm{x})$, of a structure or its competence at a given limit state is usually modelled in terms of infinite uncertain basic random variable, $x=\left(x_{1}, x_{2} \ldots \ldots x_{n}\right)$ with joint distribution function given as:

$$
F_{s}(x)=P\left\{\prod_{i=1}^{n} x_{1} \leq x_{2}\right\}
$$

and

$$
P_{f}=P\{g(x) \leq 0\}=\int f_{x}(x) d x
$$


where $f_{x}(x)$ is joint probability density function for normal distribution of random variables $x$;

$F_{s}(x)$ is the cumulative distribution function for normal distribution of random variables

$g(x)$ is the limit state function of the basic random variable

$\mathrm{g}(\mathrm{X})$ is the limit state function for all failure modes $\mathrm{g}(\mathrm{X})=0$ : represents attainment of the limit state; $\mathrm{g}(\mathrm{X})<0$ : represents failure;

$g(X)>0$ : represents safety.

The probability of failure is given by $\mathrm{P}\{\mathrm{g}(\mathrm{x})<0\}$ and therefore the reliability index, $\beta$, can be related to the probability of failure by the following equation:

$P_{f}=1-\Phi(\beta)$

where $p_{f}$ is the probability of failure, $\Phi$ is the cumulative density function of standard normal distribution and $\beta$ is the reliability index or safety index.

The limit-state function $\mathrm{g}(\mathrm{X})$ for all failure modes used for the component and system analysis is defined as the difference between the corresponding capacity and demand values:

$\mathrm{g}(\mathrm{X})=\operatorname{Re}$ sis $\tan c e-$ Loads

\subsection{Limit State Equations Based on [26]}

Failure of a structure generally designates the event that the structure does not satisfy a specific set of functional requirements. It is the event where load exceeds resistance, that is, $\mathrm{g}(\mathrm{X})<0$, and does not necessarily correspond to a physical collapse of the structural member. It implies that clearly defined limit states of structural usefulness, which are conditions of potential failure, have been exceeded. Analytical models capable of representing the different failure modes of structural components are required to evaluate the response of a structure as it approaches the collapse limit state. The failure modes considered are:

\subsubsection{Crushing failure mode;}

$$
\begin{aligned}
& g_{1}(X)=0.6 f_{c u}-\frac{P_{\text {Euler }}}{B N} \\
& g_{2}(X)=0.4 f_{c u}-\left[\frac{\pi^{2} E I}{B N L^{2}}+\frac{6 M}{B N^{2}}\right]
\end{aligned}
$$

\subsubsection{Yielding of the base plate due to bending on} compression side:

$g_{3}(X)=\frac{1.2 f_{\text {CFRP }} t_{p}^{2}}{6}-\frac{(L-D)^{2}}{8}\left\{\left[\frac{P_{\text {Euler }}}{B N}+\frac{6 M}{B N^{2}}\right]\right\}(9)$

$g_{3}(X)=\frac{1.2 f_{\text {CFRP }} t_{p}^{2}}{6}-\frac{(L-D)^{2}}{8}\left\{\left[\frac{\pi^{2} E l}{B N L^{2}}+\frac{6 M}{B N^{2}}\right]\right\}$

In (7) to (10), $\mathrm{P}_{\text {Euler }}$ is the Critical loading ( $\left.\mathrm{kN}\right), \mathrm{M}$ is the Applied bending moment $(\mathrm{kNm}), t_{p}$ is the Plate thickness ( $\mathrm{mm}), L$ is the Column height ( $\mathrm{mm}), B$ is the Plate width ( $\mathrm{mm}), \mathrm{N}$ is the Pedestal length ( $\mathrm{mm}), \mathrm{D}$ is the Pedestal depth $(\mathrm{mm}), f_{c u}$ is the Concrete compressive stress $\left(\mathrm{N} / \mathrm{mm}^{2}\right), f_{C F R P}$ is the CFRP yield strength $\left(\mathrm{N} / \mathrm{mm}^{2}\right), \mathrm{E}$ is the Elasticity modulus $(\mathrm{MPa})$ and $\mathrm{I}$ is the Second moment of inertia $\left(\mathrm{mm}^{4}\right)$

\subsubsection{Axial failure mode}

$$
\begin{aligned}
& P_{u z} \geq P \\
& P_{u z}-P=(0)
\end{aligned}
$$

Then,

$$
\begin{aligned}
& G(X)=P_{u z}-P \\
& G(X)=1-\frac{P}{P_{u z}}
\end{aligned}
$$

$$
\text { But } P=1.35 G_{k}+1.5 Q_{k} \text { and } P_{u z}=P_{E}=\frac{\pi^{2} E I}{K L}
$$
Then,

$$
\begin{array}{r}
G(X)=1-\frac{\left(1.35 G_{k}+1.5 Q_{k}\right)}{\left(\frac{\pi^{2} E_{C F R P} I_{C F R P}}{K L}\right)} \\
G(X)=1-\frac{\left(Q_{k}(1.35 \alpha+1.5)\right)}{\left(\frac{\pi^{2} E_{C F R P} I_{C F R P}}{K L}\right)}
\end{array}
$$

The symbols $G_{k}$ is the Dead load on column, $Q_{k}$ is the live load on column while $\alpha=\mathrm{G}_{\mathrm{K}} / \mathrm{Q}_{\mathrm{K}}$ is the load ratio. Euler's buckling load is used in this instance as $\mathrm{P}_{\mathrm{uz}}$ and $\mathrm{P}$ is the normal axial load for a practical load situation.

\section{MATERIALS AND METHODS}

\subsection{Material Properties}

Materials used for this study were Carbon FibreReinforced Plastics (CFRP) and steel hollow sections of same sizes and variable configurations under compression loading. The configurations include axial loading, geometry, fibre material, tube layout pattern, installation, and sectional properties of column. Table 
1 shows the basic properties used for the CFRP and steel hollow sections.

\subsection{Finite Element Models}

The models were cylinders and rectangular prisms of specified sections, various lengths, inner and outer radii, and width and depth. The columns were kept fixed at both ends considering most practical end situation and a compressive load was applied. The fixed columns are subject to ambient temperature with no considerable insulation. The columns expand due to the heat flow.

\subsection{Design of hollow circular and rectangular sections}

ABAQUS commercial finite element analysis code was used for the numerical analysis and design of circular and rectangular model sections. The software was used to analyse failure and infer on safety conditions of CFRP hollow sections in compression. The columns were designed as three-dimensional, deformable solid elements.

Table 1: Properties of CFRP and Steel

\begin{tabular}{cccccc}
\hline Material & $\begin{array}{c}\text { Density } \\
\left(\mathrm{Kg} / \mathrm{m}^{3}\right)\end{array}$ & $\begin{array}{c}\text { Young's modulus } \\
(\mathrm{Pa})\end{array}$ & Poisons ratio & $\begin{array}{c}\text { Conductivity } \\
\left(\mathrm{Wm}^{-1} \mathrm{~K}^{-1}\right)\end{array}$ & $\begin{array}{c}\text { Specific heat } \\
(\mathrm{KJ})\end{array}$ \\
\hline CFRP & 1460 & $150 \mathrm{e} 9$ & 0.35 & 160 & 1600 \\
\hline STEEL & 8000 & $210 \mathrm{e} 9$ & 0.3 & 80 & 500 \\
\hline
\end{tabular}

Table 2: Loads and design variables for CFRP and steel hollow circular sections

\begin{tabular}{|c|c|c|c|c|c|c|c|c|c|c|c|}
\hline $\begin{array}{l}\text { Height } \\
\mathrm{H}(\mathrm{mm})\end{array}$ & $\begin{array}{l}\text { Size of } \\
\text { cavity } \\
D(\mathrm{~mm})\end{array}$ & $I_{x y}\left(m m^{4}\right)$ & $\begin{array}{l}\text { Thick } \\
\text { ness } \\
\mathrm{t}(\mathrm{mm})\end{array}$ & $\mathrm{D} / \mathrm{t}$ & $\begin{array}{c}P_{\text {crit }} \\
\left(k N / m^{2}\right) \\
(\mathrm{CFRP})\end{array}$ & $\begin{array}{c}P_{\text {crit }} \\
\left(\mathrm{kN} / \mathrm{m}^{2}\right) \\
\text { (Steel) }\end{array}$ & $\begin{array}{c}I_{x y} \\
\left(\mathrm{~mm}^{4}\right)\end{array}$ & $\begin{array}{l}\text { Thick- } \\
\text { ness t } \\
(\mathrm{mm})\end{array}$ & $\mathrm{D} / \mathrm{t}$ & $\begin{array}{c}P_{\text {crit }} \\
\left(\mathrm{kN} / \mathrm{m}^{2}\right) \\
(\mathrm{CFRP})\end{array}$ & $\begin{array}{c}\mathrm{P}_{\text {crit }} \\
\left(\mathrm{kN} / \mathrm{m}^{2}\right) \\
(\text { Steel }) \\
\end{array}$ \\
\hline 3000 & C90 & $6.6 \mathrm{e} 5$ & 5 & 18 & $1.1 \mathrm{e} 11$ & $1.5 \mathrm{e} 11$ & $1.2 \mathrm{e} 6$ & 10 & 9 & $2.0 \mathrm{e} 11$ & $2.8 \mathrm{e} 11$ \\
\hline 3000 & C127 & $1.9 \mathrm{e} 5$ & 5 & 25.4 & $3.1 \mathrm{e} 10$ & $4.4 \mathrm{e} 10$ & $3.6 \mathrm{e} 6$ & 10 & 12.7 & $6.0 \mathrm{e} 11$ & $8.3 \mathrm{e} 11$ \\
\hline 3000 & C150 & $3.2 \mathrm{e} 6$ & 5 & 30 & $5.3 \mathrm{e} 11$ & $7.4 \mathrm{e} 11$ & $6.0 \mathrm{e} 6$ & 10 & 15 & $9.9 \mathrm{e} 11$ & $1.4 \mathrm{e} 12$ \\
\hline 3000 & C250 & $15 \mathrm{e} 6$ & 5 & 50 & $2.5 \mathrm{e} 12$ & $3.5 \mathrm{e} 12$ & $29 \mathrm{e} 6$ & 10 & 25 & $4.8 \mathrm{e} 12$ & $6.7 \mathrm{e} 12$ \\
\hline 3000 & C300 & $28.9 \mathrm{e} 6$ & 5 & 60 & $4.8 \mathrm{e} 12$ & $6.7 \mathrm{e} 12$ & $50 \mathrm{e} 6$ & 10 & 30 & $8.2 \mathrm{e} 12$ & $1.2 \mathrm{e} 13$ \\
\hline 4500 & $\mathrm{C} 90$ & $6.6 \mathrm{e} 5$ & 5 & 18 & $4.8 \mathrm{e} 10$ & $6.8 \mathrm{e} 10$ & $1.2 \mathrm{e} 6$ & 10 & 9 & $8.8 \mathrm{e} 13$ & $1.2 \mathrm{e} 11$ \\
\hline 4500 & C127 & $1.9 \mathrm{e} 5$ & 5 & 25.4 & $1.4 \mathrm{e} 10$ & $2.0 \mathrm{e} 10$ & $3.6 \mathrm{e} 6$ & 10 & 12.7 & $2.6 \mathrm{e} 11$ & $3.7 \mathrm{e} 11$ \\
\hline 4500 & C150 & $3.2 \mathrm{e} 6$ & 5 & 30 & $2.3 \mathrm{e} 11$ & $3.3 \mathrm{e} 11$ & $6.0 \mathrm{e} 6$ & 10 & 15 & $4.4 \mathrm{e} 11$ & $6.1 \mathrm{e} 11$ \\
\hline 4500 & C250 & $15 \mathrm{e} 6$ & 5 & 50 & $1.1 \mathrm{e} 12$ & $1.5 \mathrm{e} 12$ & $29 \mathrm{e} 6$ & 10 & 25 & $2.1 \mathrm{e} 12$ & $3.0 \mathrm{e} 12$ \\
\hline 4500 & C300 & $28.9 \mathrm{e} 6$ & 5 & 60 & $2.1 \mathrm{e} 12$ & $3.0 \mathrm{e} 12$ & $50 \mathrm{e} 6$ & 10 & 30 & $3.7 \mathrm{e} 12$ & $5.1 \mathrm{e} 12$ \\
\hline 6000 & C90 & $6.6 \mathrm{e} 5$ & 5 & 18 & $2.7 \mathrm{e} 10$ & $3.8 \mathrm{e} 10$ & $1.2 \mathrm{e} 6$ & 10 & 9 & $5.0 \mathrm{e} 10$ & $7.0 \mathrm{e} 10$ \\
\hline 6000 & C127 & $1.9 \mathrm{e} 5$ & 5 & 25.4 & $7.8 \mathrm{e} 9$ & $1.1 \mathrm{e} 10$ & $3.6 \mathrm{e} 6$ & 10 & 12.7 & $1.5 \mathrm{e} 11$ & $2.1 \mathrm{e} 11$ \\
\hline 6000 & C150 & $3.2 \mathrm{e} 6$ & 5 & 30 & $1.3 \mathrm{e} 11$ & $1.8 \mathrm{e} 11$ & $6.0 \mathrm{e} 6$ & 10 & 15 & $2.5 \mathrm{e} 11$ & $3.5 \mathrm{e} 11$ \\
\hline 6000 & C250 & $15 \mathrm{e} 6$ & 5 & 50 & $6.2 \mathrm{e} 11$ & $8.6 \mathrm{e} 11$ & $29 \mathrm{e} 6$ & 10 & 25 & $1.2 \mathrm{e} 12$ & $1.7 \mathrm{e} 12$ \\
\hline 6000 & C300 & $28.9 \mathrm{e} 6$ & 5 & 60 & $1.2 \mathrm{e} 12$ & $1.7 \mathrm{e} 12$ & $50 \mathrm{e} 6$ & 10 & 30 & $2.1 \mathrm{e} 12$ & $2.9 \mathrm{e} 12$ \\
\hline
\end{tabular}

Table 3: Loads and design variables for CFRP and steel hollow rectangular sections

\begin{tabular}{|c|c|c|c|c|c|c|c|c|c|}
\hline $\begin{array}{l}\text { Height } \\
\mathrm{H}(\mathrm{mm})\end{array}$ & $\begin{array}{l}\text { Size of cavity } \\
(\mathrm{d} \times \mathrm{b}) \mathrm{mm}\end{array}$ & $I_{x y}\left(m m^{4}\right)$ & $\begin{array}{c}\text { Thick-ness } \\
\mathrm{t}(\mathrm{mm})\end{array}$ & $\begin{array}{c}P_{\text {crit }} \\
\left(\mathrm{kN} / \mathrm{m}^{2}\right) \\
(\mathrm{CFRP})\end{array}$ & $\begin{array}{c}\mathrm{P}_{\text {crit }} \\
\left(\mathrm{kN} / \mathrm{m}^{2}\right)(\text { Steel })\end{array}$ & $I_{x y}\left(m^{4}\right)$ & $\begin{array}{l}\text { Thick- } \\
\text { nesst } \\
(\mathrm{mm})\end{array}$ & $\begin{array}{c}P_{\text {crit }} \\
\left(\mathrm{kN} / \mathrm{m}^{2}\right) \\
(\mathrm{CFRP}) \\
\end{array}$ & $\begin{array}{c}P_{\text {crit }} \\
\left(\mathrm{kN} / \mathrm{m}^{2}\right) \\
(\text { Steel }) \\
\end{array}$ \\
\hline 3000 & $80 \times 60$ & $1.1 \mathrm{e} 6$ & 5 & $1.8 \mathrm{e} 11$ & $2.5 \mathrm{e} 11$ & $1.8 \mathrm{e} 6$ & 10 & $3.0 \mathrm{e} 11$ & 4.e11 \\
\hline 3000 & $100 \times 50$ & $1.7 \mathrm{e} 6$ & 5 & $2.8 \mathrm{e} 11$ & $4.0 \mathrm{e} 11$ & $2.9 \mathrm{e} 6$ & 10 & $4.8 \mathrm{e} 11$ & $6.7 e 11$ \\
\hline 3000 & $100 \times 75$ & $2.3 e 6$ & 5 & $3.8 \mathrm{e} 11$ & $5.3 \mathrm{e} 11$ & $6.3 \mathrm{e} 6$ & 10 & $1.0 \mathrm{e} 12$ & $1.5 \mathrm{e} 12$ \\
\hline 3000 & $350 \times 200$ & $9.2 \mathrm{e} 8$ & 5 & $1.5 \mathrm{e} 14$ & $2.1 \mathrm{e} 14$ & $1.7 \mathrm{e} 8$ & 10 & $2.8 \mathrm{e} 13$ & $4.0 \mathrm{e} 13$ \\
\hline 3000 & $450 \times 300$ & $2.2 \mathrm{e} 8$ & 5 & 3.6e13 & $5.1 \mathrm{e} 13$ & $4.3 \mathrm{e} 8$ & 10 & $7.1 \mathrm{e} 13$ & $10 \mathrm{e} 13$ \\
\hline 4500 & $80 \times 60$ & $1.1 \mathrm{e} 6$ & 5 & $8.0 \mathrm{e} 10$ & $1.1 \mathrm{e} 8$ & $1.8 \mathrm{e} 6$ & 10 & $1.3 e 11$ & $1.8 \mathrm{e} 11$ \\
\hline 4500 & $100 \times 50$ & $1.7 \mathrm{e} 6$ & 5 & $1.2 \mathrm{e} 11$ & $1.7 \mathrm{e} 11$ & $2.9 \mathrm{e} 6$ & 10 & $2.1 \mathrm{e} 11$ & $3.0 \mathrm{e} 11$ \\
\hline 4500 & $100 \times 75$ & $2.3 \mathrm{e} 6$ & 5 & $1.7 \mathrm{e} 11$ & $2.4 \mathrm{e} 11$ & $6.3 \mathrm{e} 6$ & 10 & $4.6 \mathrm{e} 11$ & $6.4 \mathrm{e}^{11}$ \\
\hline 4500 & $350 \times 200$ & $9.2 \mathrm{e} 8$ & 5 & $6.7 \mathrm{e} 13$ & $9.4 \mathrm{e} 13$ & 1.7 e8 & 10 & $1.2 \mathrm{e} 13$ & $1.7 \mathrm{e} 13$ \\
\hline 4500 & $450 \times 300$ & $2.2 \mathrm{e} 8$ & 5 & $1.6 \mathrm{e} 13$ & $2.3 \mathrm{e} 13$ & $4.3 \mathrm{e} 8$ & 10 & $3.1 \mathrm{e} 13$ & $4.4 \mathrm{e} 13$ \\
\hline 6000 & 80 x 60 & $1.1 \mathrm{e} 6$ & 5 & $4.5 \mathrm{e} 10$ & $6.3 \mathrm{e} 10$ & $1.8 \mathrm{e} 6$ & 10 & $7.4 \mathrm{e} 10$ & $1.0 \mathrm{e} 11$ \\
\hline 6000 & $100 \times 50$ & $1.7 \mathrm{e} 6$ & 5 & $7.0 \mathrm{e} 10$ & $9.8 \mathrm{e} 10$ & $2.9 \mathrm{e} 6$ & 10 & $1.2 \mathrm{e} 11$ & $1.7 \mathrm{e}^{11}$ \\
\hline 6000 & $100 \times 75$ & $2.3 \mathrm{e} 6$ & 5 & $9.5 \mathrm{e} 10$ & $1.3 \mathrm{e} 11$ & $6.3 \mathrm{e} 6$ & 10 & $2.6 \mathrm{e} 11$ & $3.6 \mathrm{e} 11$ \\
\hline 6000 & $350 \times 200$ & $9.2 \mathrm{e} 8$ & 5 & $3.8 \mathrm{e} 13$ & $5.3 e 13$ & $1.7 \mathrm{e} 8$ & 10 & $7.0 \mathrm{e} 12$ & $9.8 \mathrm{e} 12$ \\
\hline 6000 & $450 \times 300$ & $2.2 \mathrm{e} 8$ & 5 & $9.0 \mathrm{e} 12$ & $1.3 \mathrm{e} 13$ & $4.3 e 8$ & 10 & $1.8 \mathrm{e} 13$ & $2.5 \mathrm{e} 13$ \\
\hline
\end{tabular}


Each analytical model includes 10 modules: Part, Property, Assembly, Step, Interaction, Load, Mesh, Job, Visualization, and sketch. A critical axial load used to test hollow sections is Euler's buckling load:

$P_{\text {crit }}=P_{E}=\frac{\pi^{2} E_{C F R P} I_{C F R P}}{(K L)^{2}}$

In (17), E EFRP is the Young's modulus of CFRP, ICFRP is the moment of inertia of CFRP

$$
\begin{aligned}
& \mathrm{I}_{\text {circular }}=\pi\left(d_{0}^{4}-d_{1}^{4}\right) / 64 \\
& \mathrm{I}_{\text {rectangular }}=\left(b d^{3}-b_{1} h^{3}\right) / 12
\end{aligned}
$$

In (18) and (19), $\mathrm{K}=1$, for a pined constraint (boundary condition); $\mathrm{L}$ is the Length of column, $\mathrm{d}_{0}$ is the outer diameter of hollow section; $d_{1}$ is the inner diameter of hollow section, $b$ is the outer breadth of rectangular hollow section; $d$ is the outer height of rectangular hollow section, $b_{1}$ is the inner breadth of rectangular hollow section and $h$ is the inner height of rectangular hollow section

The result for each model tested is presented with a deformation scale factor; the bigger the deformation scale factor the lower the failure level of the tested model and it consequently explains the safety of such models under critical loading, constraints and anticipated ambient temperature condition. The safety design variables considered include:

(i) Deformation

(ii) Shape factor

(iii) Size of cavity

(iv) Length effect

(v) Diameter to thickness (D/t) ratio (circular sections)

(vi) Material thickness

The lengths of columns used were $3 \mathrm{~m}, 4.5 \mathrm{~m}$ and $6.0 \mathrm{~m}$, and the thicknesses were $5 \mathrm{~mm}$ and $10 \mathrm{~mm}$. All axial areal loads (pressure) applied on columns were critical axial buckling loads. These loads and other data are shown in Tables 2 and 3. All variables were subject to applied areal load (pressure) on sectional areas.

\section{RESULTS AND DISCUSSION}

\subsection{Deformation}

Deformation scale factors of CFRP and steel hollow sections with the same sectional size and properties are compared to assess the safety of CFRP hollow section with the corresponding critical buckling load for individual materials assuming that material thicknesses are constant for CFRP and steel. The major deformations are column shortening and a slight buckle at the base of the column, with a deformation scale factor of $+8.339 \mathrm{e}-4$ as shown in Figures 1 to 3 .

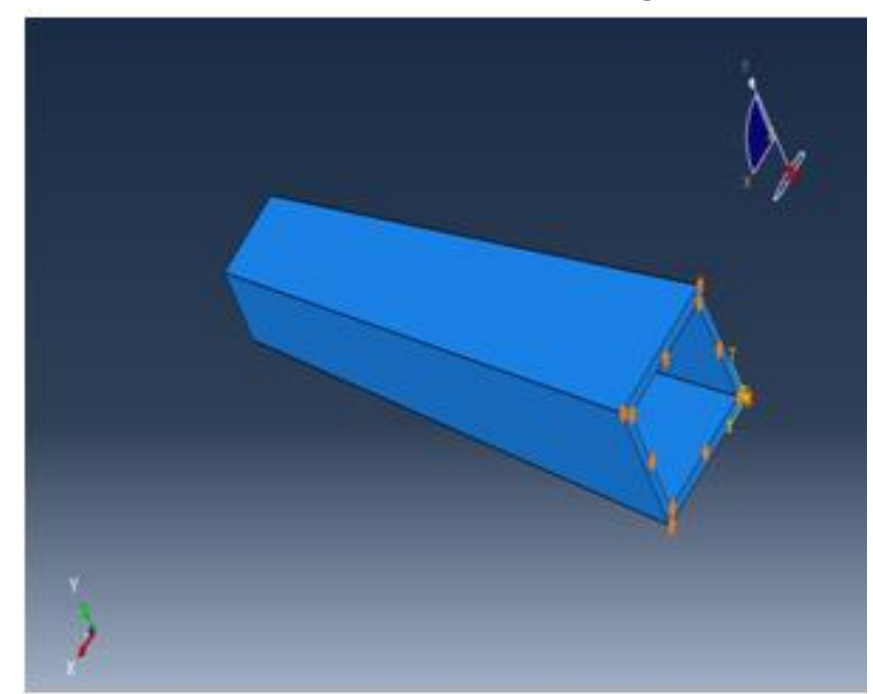

Figure 1: Fixed end of $\mathrm{C} 80 \times 60$ (steel) hollow

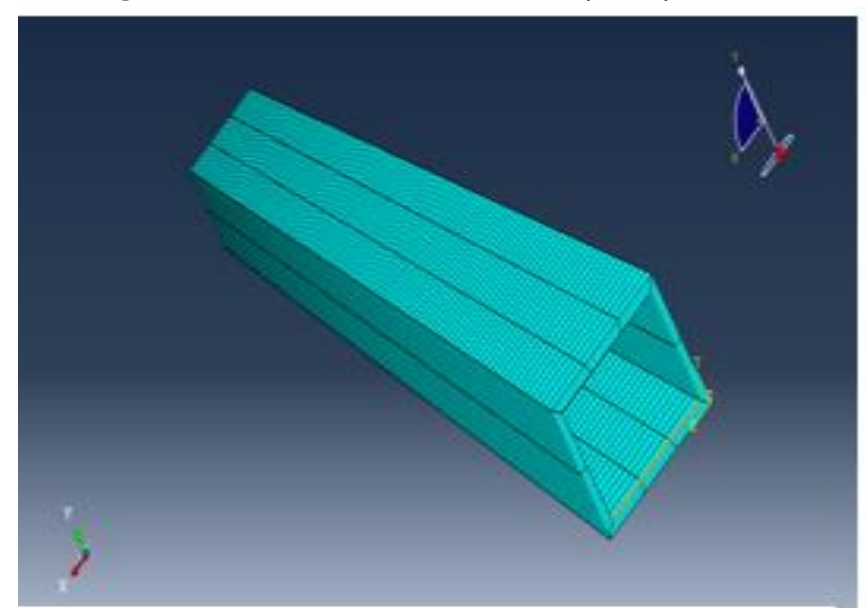

Figure 2: Meshed hollow section

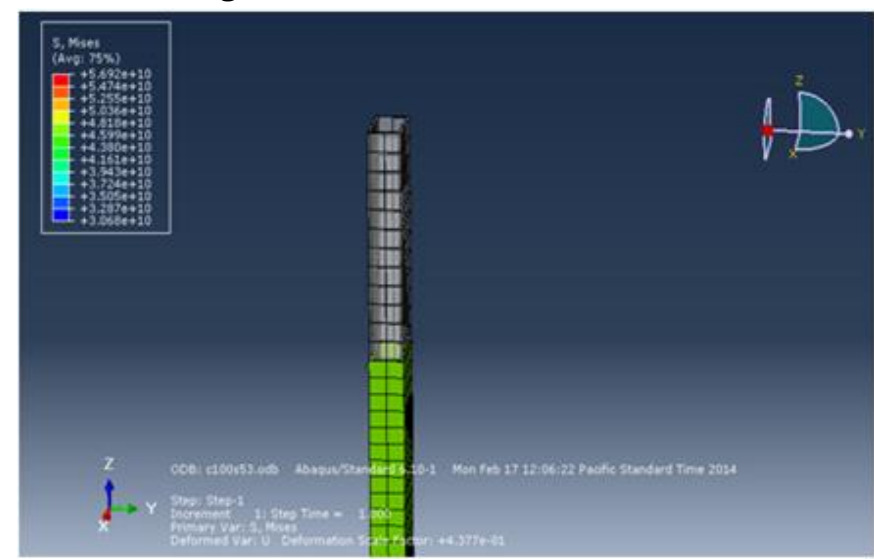

Figure 3: Shortening of steel section after applying axial pressure of $2.5 \mathrm{e} 8 \mathrm{kN} / \mathrm{m}^{2}$

A comparison between C80 x 60 (CFRP) and C80 x 60 (Steel) at $3 \mathrm{~m}$ clear height infers that at $3 \mathrm{~m}$ of clear column height under uniformly distributed axial load on $5 \mathrm{~mm}$ thickness of both materials:

(i) CFRP slightly buckles at the base of the column; 
(ii) There is considerable column shortening and increase in lateral dimension of both CFRP and steel hollow sections;

(iii) Steel is obviously safer than CFRP irrespective of the benefits CFRP offers such as its low self-weight in comparison with steel.

This explains a lower deformation scale factor of $+8.339 \mathrm{e}-4$ for CFRP compared to $+4.337 \mathrm{e}-01$ for steel as presented by ABAQUS/CAE.

\subsection{Shape Factor}

The deformation of CFRP is compared to the deformation of steel for circular and rectangular hollow sections in a bid to assess if the shape of the hollow sections affects the deformation and failure of the sections in comparison to the deformation of steel hollow sections in compression as can be seen in Figures 4 to 8.

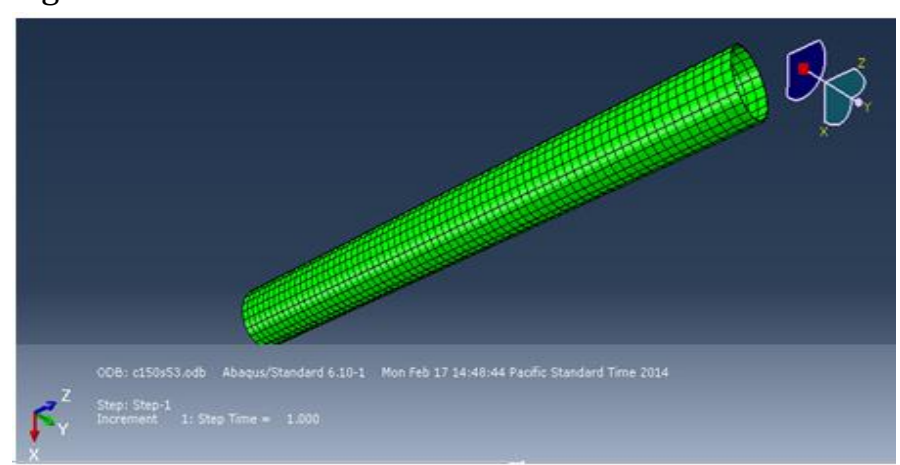

Figure 4: Undeformed plot of 150 (CFRP) at $4.5 \mathrm{~m}$ clear height and thickness of $5 \mathrm{~mm}$ with an applied pressure of $1.5 e 9 \mathrm{kN} / \mathrm{m}^{2}$

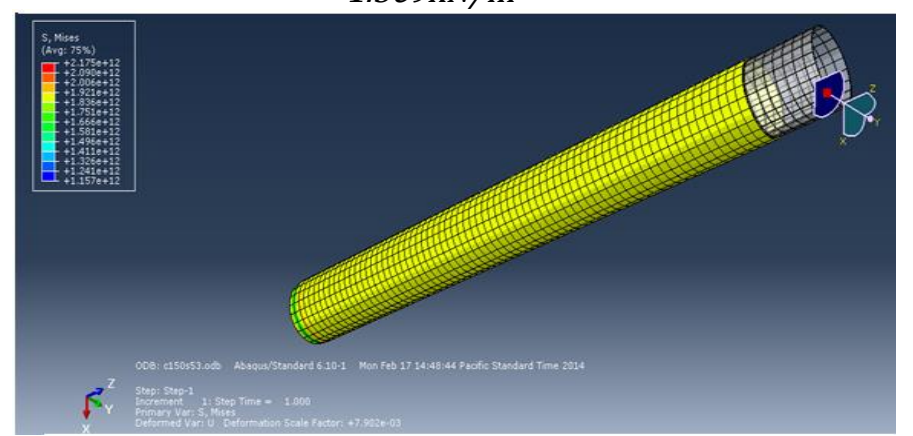

Figure 5: Deformed circular hollow section model with slight buckle at the base

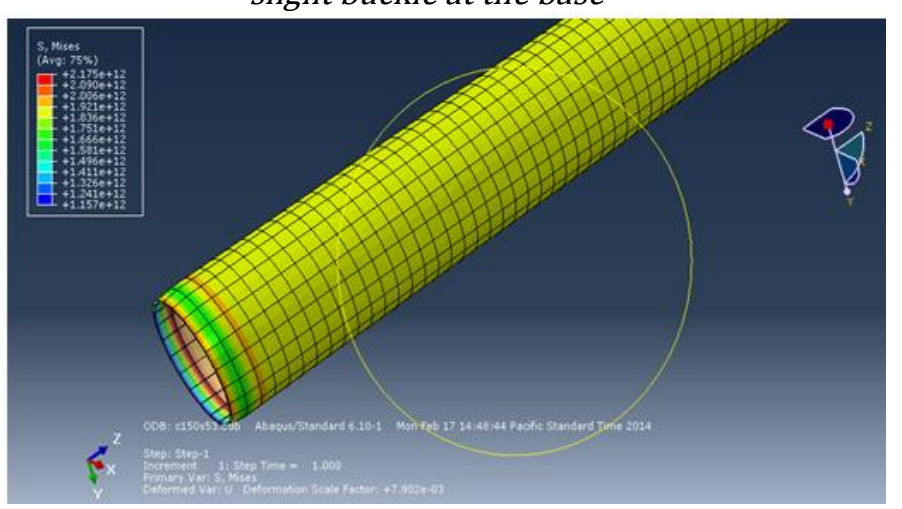

Figure 6: Slight buckle at the base of model

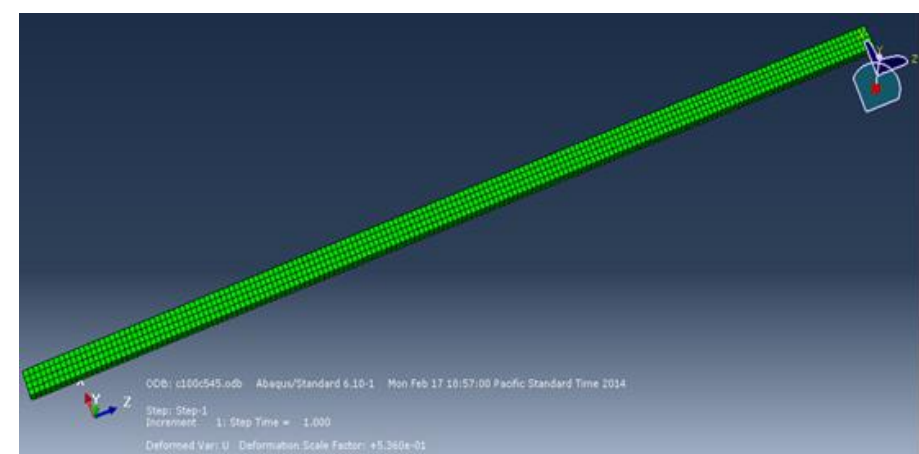

Figure 7: Undeformed C100 x 50 (CFRP) at 4.5m height and $5 \mathrm{~mm}$ material thickness

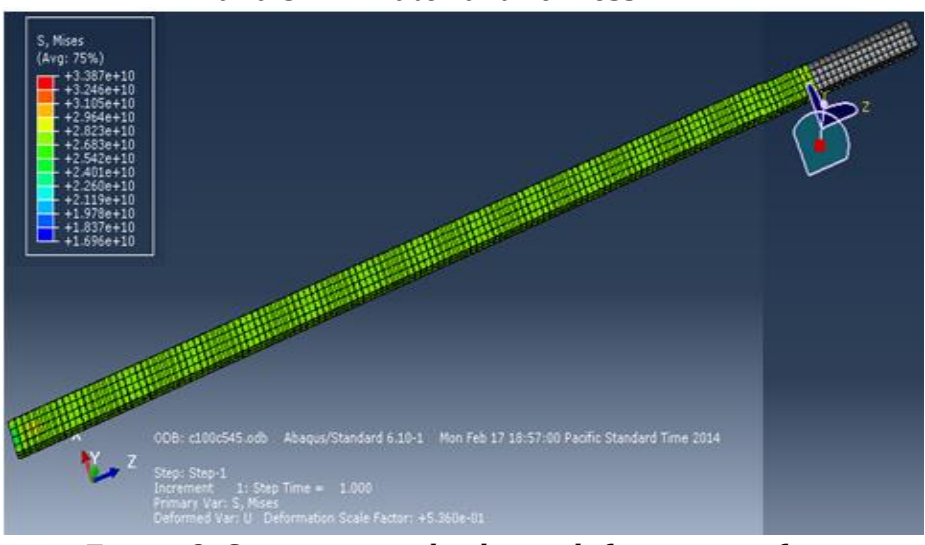

Figure 8: Superimposed column deformation of rectangular hollow section

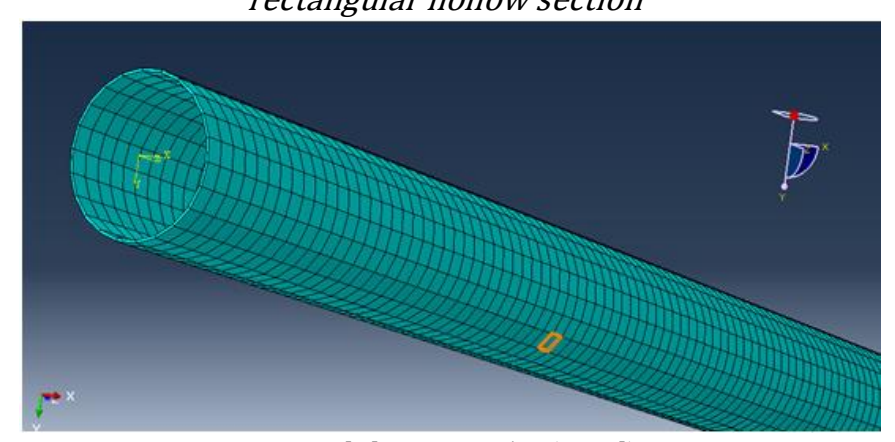

Figure 9: Model C100 x 50 (steel) section

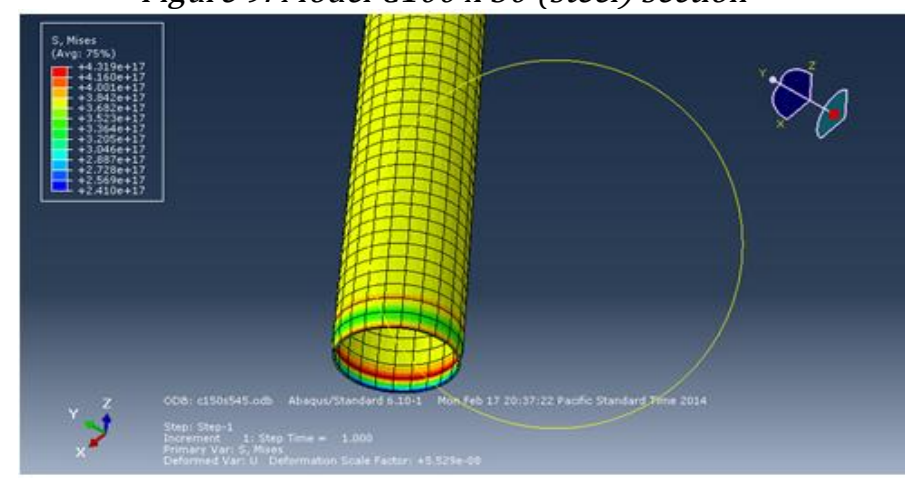

Figure 10: Buckling at the base of circular hollow section and lateral increase in dimension

For a rectangular hollow section, C100 x 50 (CFRP), there is no considerable buckling of column at the base. The major deformations are column shortening and lateral increase in dimension. For a good comparison a comparable circular and rectangular hollow cross-sectional area of CFRP is used in this case; where the deformation scale factors are: Circular $=+7.9 \mathrm{e}-03$; Rectangular $=+5.360 \mathrm{e}-01$. 


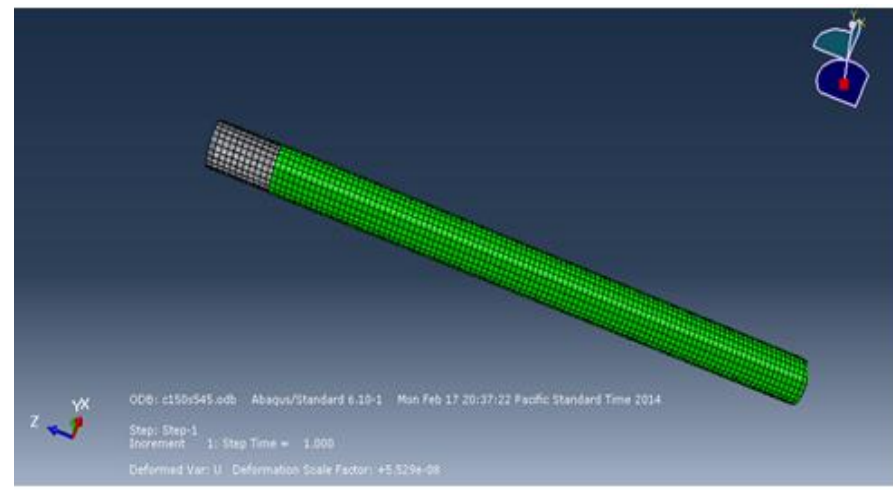

Figure 11: Superimposed deformed plot on undeformed plot depicting column shortening and lateral increase in dimension after applying pressure of $3.3 \mathrm{e} 8 \mathrm{kN} / \mathrm{m}^{2}$

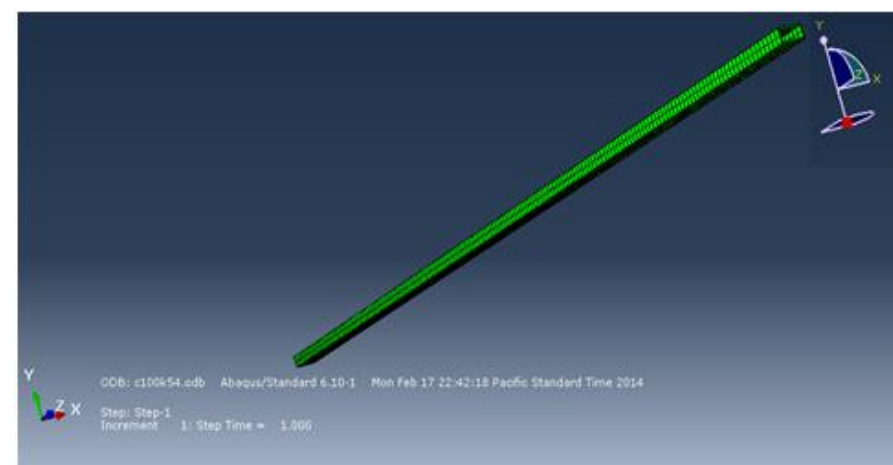

Figure 12: Undeformed plot of $\mathrm{C} 100 \times 50,5 \mathrm{~mm}$ thick at $4.5 \mathrm{~m}$ clear height.

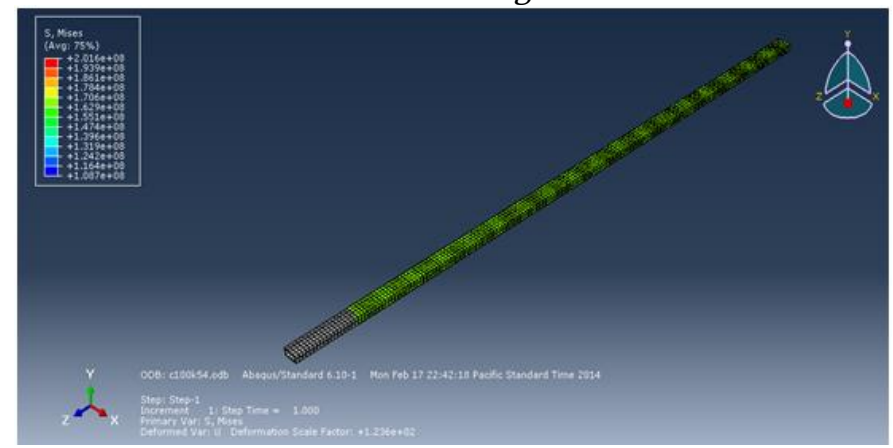

Figure 13: Superimposed deformed plot on undeformed plot after applying an axial pressure of $6.7 \mathrm{e} 10 \mathrm{kN} / \mathrm{m}^{2}$

This implies an approximate increase in scale deformation factor by $67 \%$. The deformation factors for steel are as shown in Figures 9 to 13. The deformation scale factor for circular hollow steel section is $+5.529 \mathrm{e}-08$ and rectangular hollow steel section is $+1.236 \mathrm{e}+02$. The deformation scale factor for steel increased over $100 \%$.

Comparable materials cross sectional area of circular and rectangular hollow sections are tested both for CFRP and steel and it is observed that:

(i) Circular CFRP hollow section buckles slightly at the base of the column with the deformation contours clearly showing that in Figure 14.

(ii) All hollow sections (circular and rectangular) are observed to shorten and increase in lateral dimension especially at the base of the deformed model.

(iii) The deformation scale factor for comparable circular and rectangular hollow section of CFRP increases approximately by $67 \%$ and that of steel increases at over $200 \%$ (comparing circular hollow section to rectangular hollow section).

This implies that at the same or comparable crosssectional areas, CFRP circular hollow sections will deform more under compressive critical loads. The increase in the deformation scale factor explains that on a basis of shape factor rectangular hollow sections are always safer and on this note the increase in deformation of steel circular hollow section to rectangular steel section is quite large and presents a good reason why CFRP hollow sections of comparable cross sectional areas are of an advantage serving as compressive structural elements. Both sections offer closer range of safety and can be used interchangeably.

\subsection{Size of Cavity}

To determine the effect of hollow size of CFRP hollow sections it will be unnecessary to make a comparison with steel as both materials have their mechanical and material properties. A comparison between $\mathrm{C} 90$ (CFRP) and C300 (CFRP) at $6 \mathrm{~m}$ clear height will be made to relate the safety of CFRP hollow sections with the size of the hollow. The column remains undeformed with a deformation scale factor of $+1.000 \mathrm{e}+00$, which implies no deformation of any kind on the model.

Model C300 shows deformation and stresses at points of pressure application, a deformation scale factor of $+1.000 \mathrm{e}+00$ imply there is no deformation too. Figures 14 to 19 give the details of the finite element analysis outputs for the structural safety.

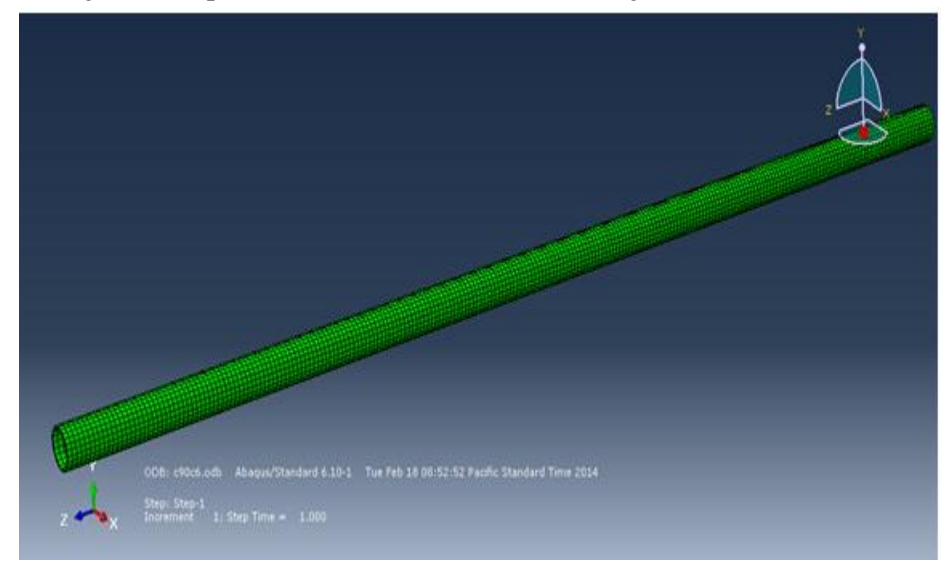

Figure 14: Undeformed plot of C90 (CFRP) before pressure was applied 


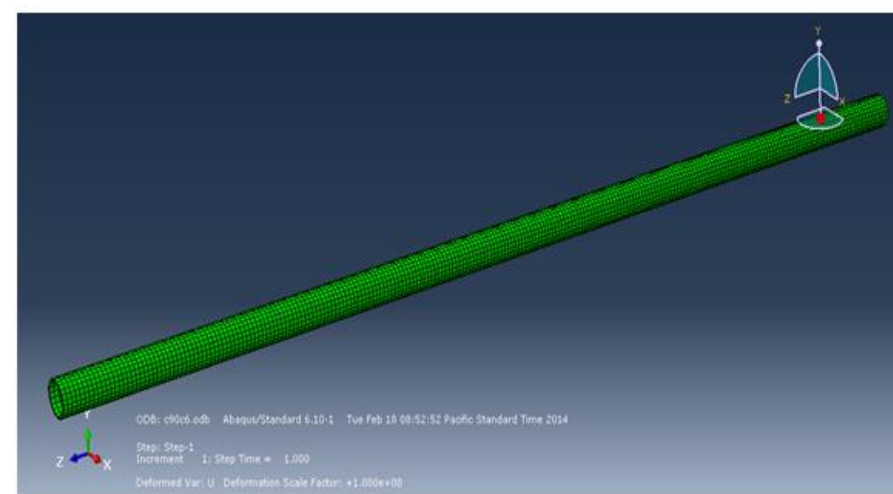

Figure 15: Undeformed plot of C90 (CFRP) after applying $4.9 e 7 \mathrm{kN} / \mathrm{m}^{2}$

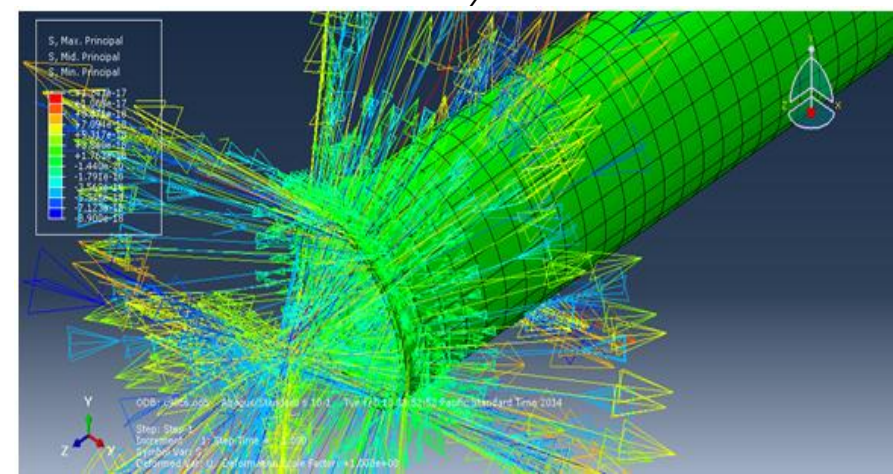

Figure 16: High deformation stresses at top of section where $4.9 e 7 \mathrm{kN} / \mathrm{m}^{2}$ was applied.

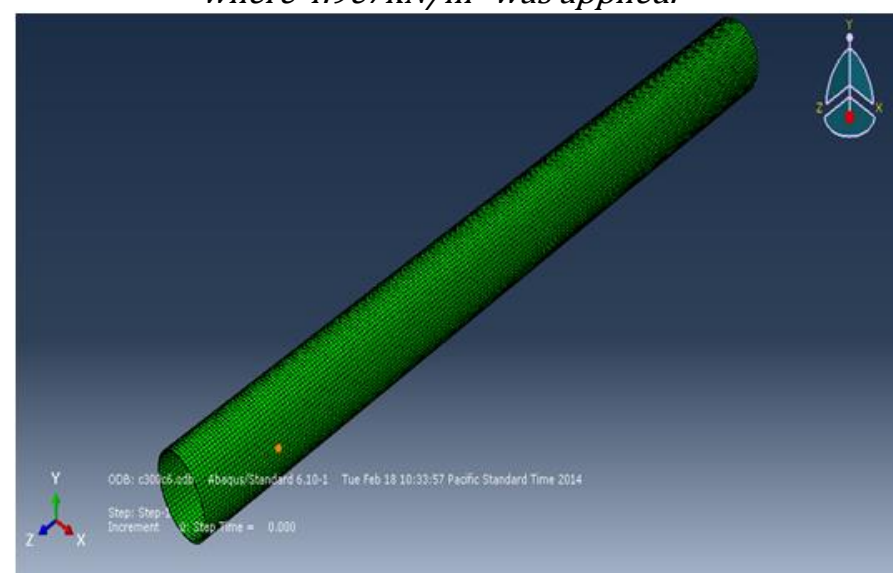

Figure 17: Undeformed plot of C300 before pressure was applied

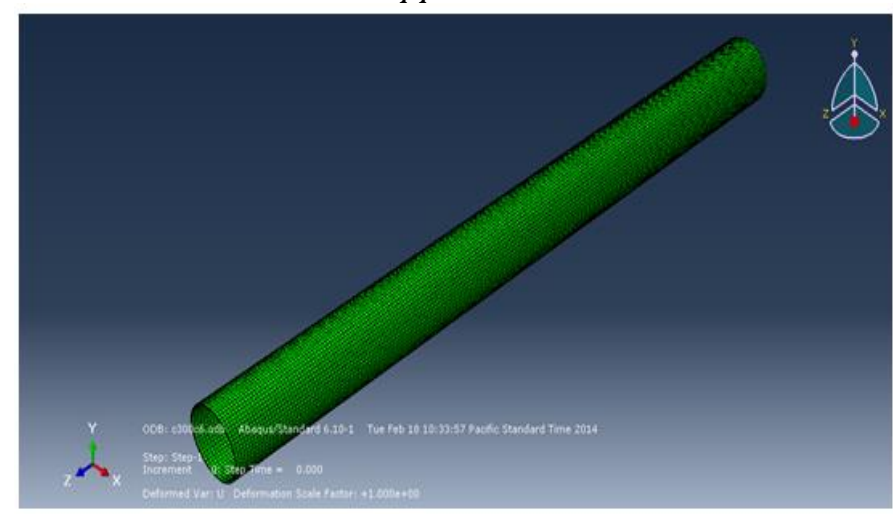

Figure 18: Deformed plot of the circular hollow section with no deformation and deformation scale factor of $1.000 e+00$

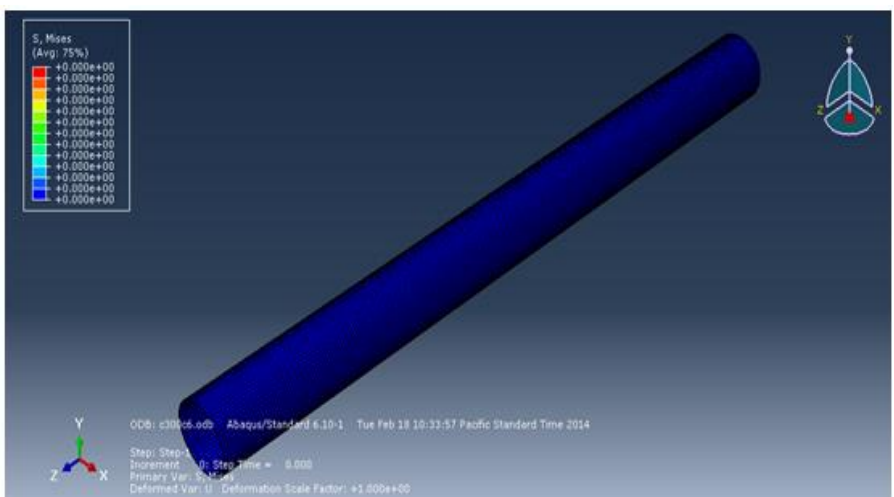

Figure 19: Deformation plot with contour deformation after applying $2.9 \mathrm{e} 9 \mathrm{kN} / \mathrm{m}^{2}$

\subsection{Comparison}

Model C300 (CFRP) with uniform material thickness of $10 \mathrm{~mm}$ has a larger hollow size compared to Model C90 (CFRP) of the same uniform material thickness, ABAQUS/CAE results on application of critical loads are:

(i) No significant deformation such as buckling at mid-height, buckling at the base, shortening or shear deformation at the top where pressure is applied for both models.

(ii) The contour deformation for C90 (CFRP) depicts a spectrum of high stresses at the point of pressure application in Figure 16 and no stresses for C300 (CFRP).

(iii) Both models have a deformation scale factor of $+1.000 \mathrm{e}+00$, which explains why there is no deformation.

This infers that cavity size does not affect the deformation or failure of CFRP hollow section in compression but smaller hollow sections will have high stresses at regions of load application, that is, at the top. Materials with discrete and uniform properties of CFRP at critical buckling loads are safe compression structural elements.

\subsection{Length Effect}

A comparison between the effect of lengths on deformation of CFRP and steel will be compared to highlight the safety of CFRP hollow sections in compression.

4.5.1 CFRP: Use models of equal sectional areas and varying clear heights as a basis for analysis. Figures 20 to 23 show the effect of lengths on the deformation of CFRP. 
$\mathrm{C} 350 \times 200,4.5 \mathrm{~m}$

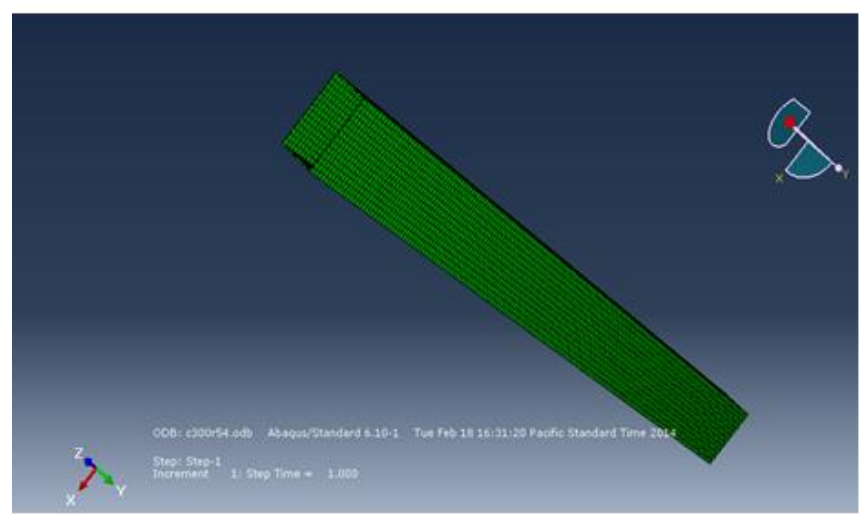

Figure 20: Undeformed plot of rectangular hollow section C350 × 200 (CFRP) $4.5 \mathrm{~m}$ clear height.

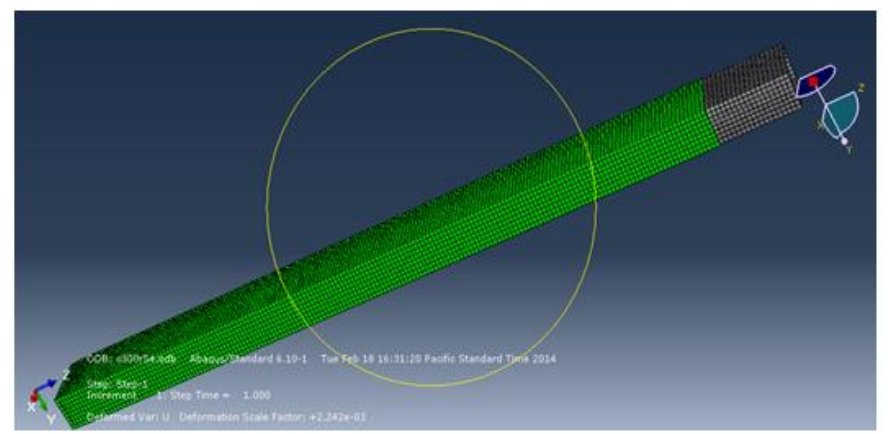

Figure 21: Deformed plot of hollow section after applying $6.7 \mathrm{kN} / \mathrm{m}^{2}$ of pressure with deformation scale factor of $+2.242 e-3$.

\section{C350 $\times 200(C F R P), 6 m$}

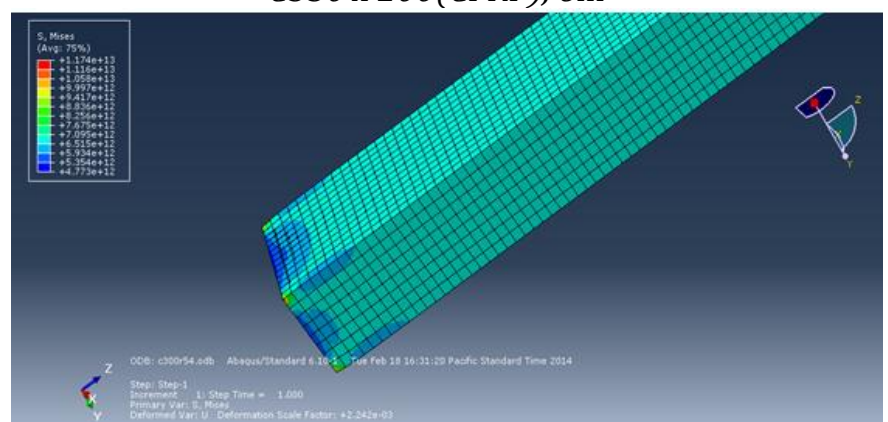

Figure 22:Slight buckling deformation of the model and lateral increase in dimension.

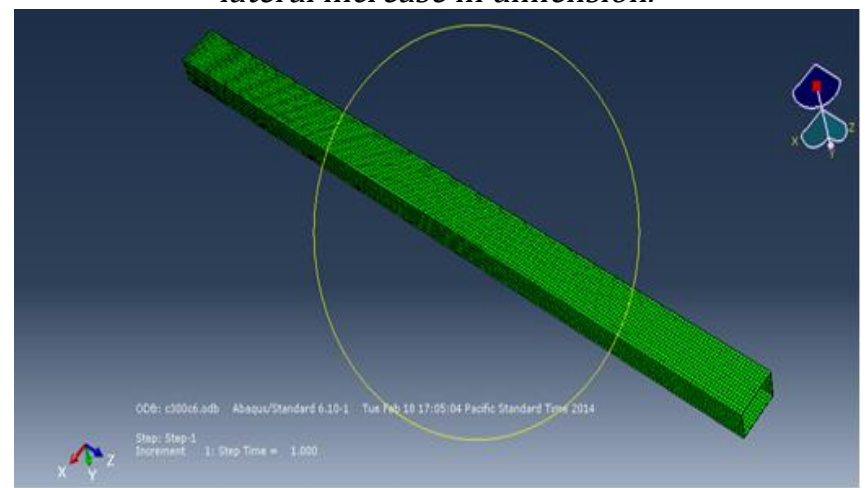

Figure 23: Undeformed plot of rectangular section C350 x 200 (CFRP) 6m clear height

The $4.5 \mathrm{~m}$ C350 × 200 (CFRP) rectangular hollow sections deformed more than the $6 \mathrm{~m}$ hollow section due to the slight considerable buckling deformation at the base of the column. Usually it is expected that longer columns will be more susceptible to axial load deformation but this case presents a different scenario of the general judgment. The deformation scale factors of both models are quite comparable and it implies that the effect of length on the failure of CFRP hollow section in compression is minimal given that all required standards are met and installations are done properly.

For steel, deformation might be minimal in longer column (that is, $6 \mathrm{~m}$ ) but it deforms more than the shorter column (that is $4.5 \mathrm{~m}$ ) because there is no deformation at the base of the column for $4.5 \mathrm{~m}$ hollow section steel at critical axial load. Steel still exhibits a close deformation factor range but it is obviously larger in comparison with the deformation factor range in CFRP hollow sections for $4.5 \mathrm{~m}$ and $6 \mathrm{~m}$. Figures 24 to 31 indicate the effect of lengths on the deformation of hollow steel sections.

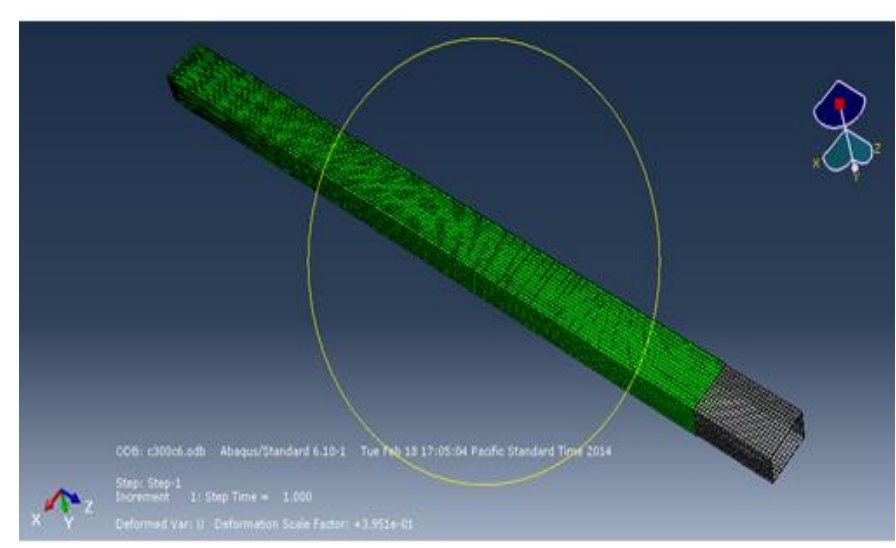

Figure 24: Deformed plot of hollow section after applying $3.8 \mathrm{e} 10 \mathrm{kN} / \mathrm{m}^{2}$ of Pressure with a deformation scale factor

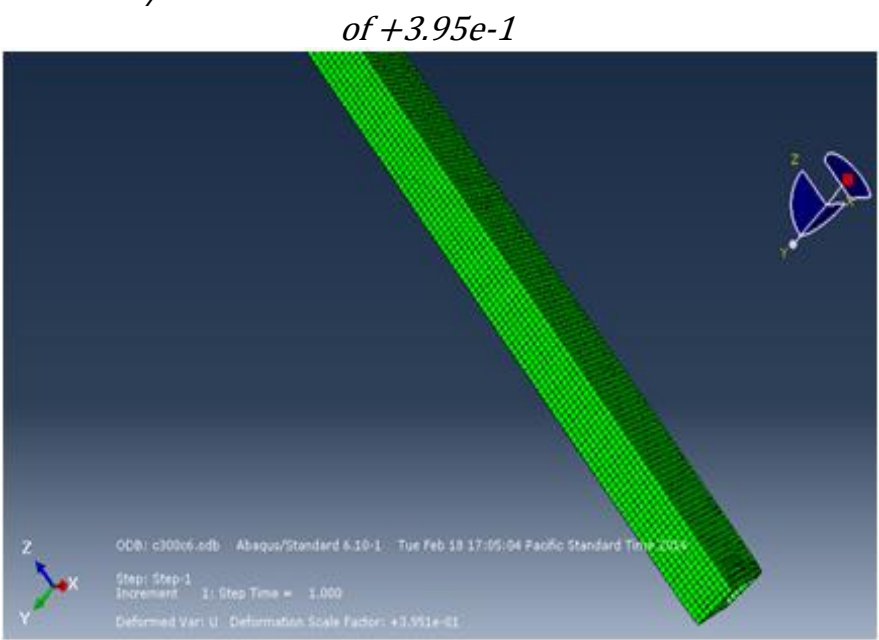

Figure 25: No buckling deformation at the base of the model and lateral increase in dimension is due to shortening. 


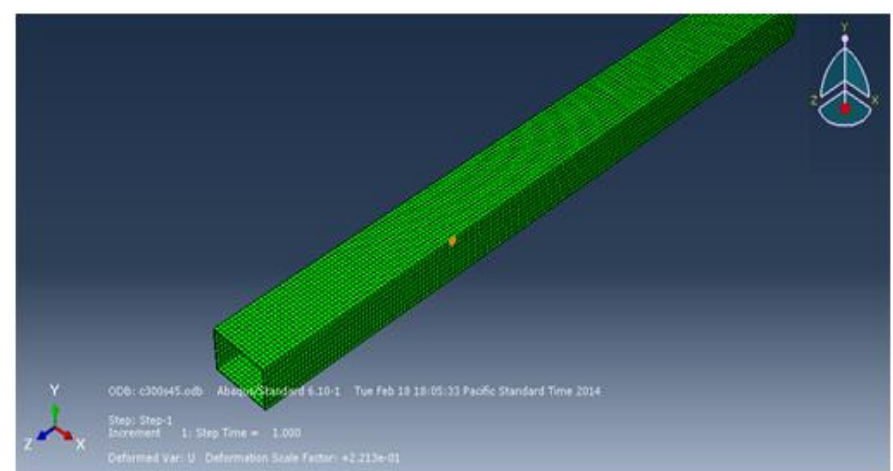

Figure 26: Undeformed plot of rectangular hollow section C350 × 200 (steel) $4.5 \mathrm{~m}$ clear height

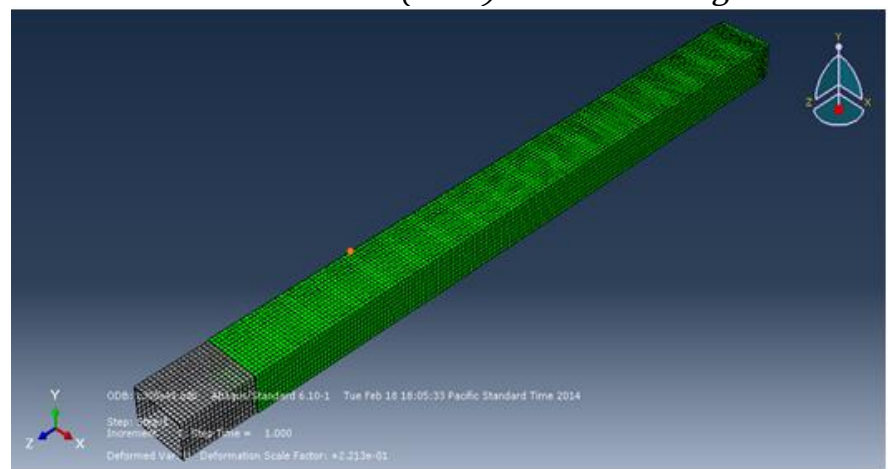

Figure 27: Deformed plot of hollow section after applying $9.5 \mathrm{e} 10 \mathrm{kN} / \mathrm{m}^{2}$ of pressure with a deformation scale factor of $2.213 e-01$.

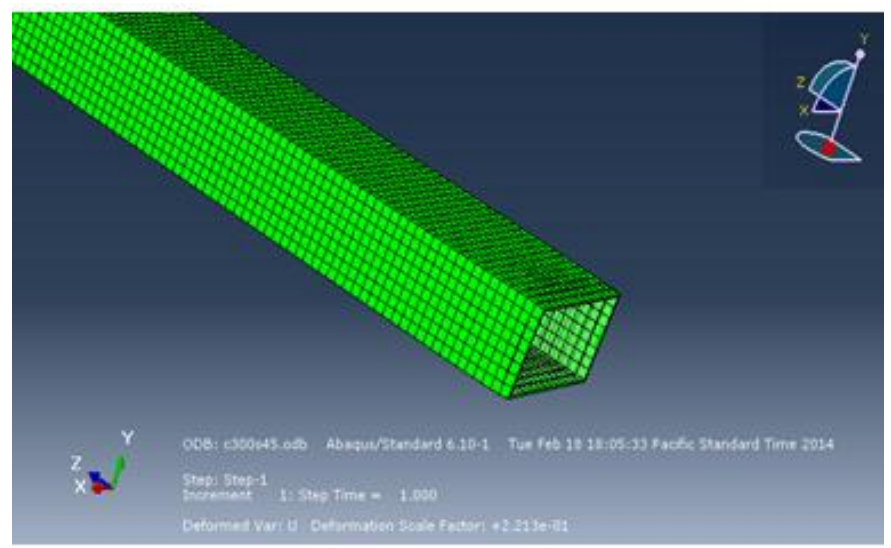

Figure 28: No buckling deformation at the base of the model and lateral increase in dimensions is due to shortening.

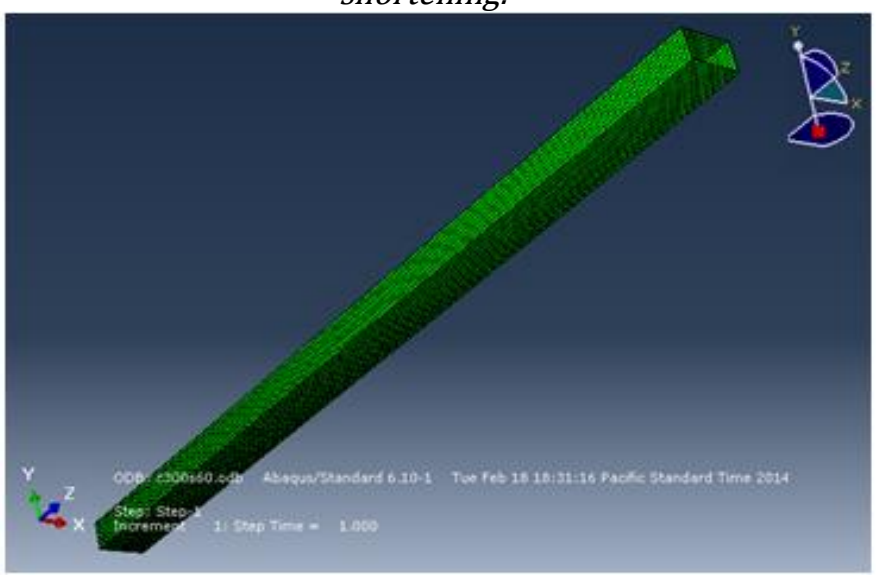

Figure 29: Undeformed plot of rectangular hollow section C350 × 200 (steel), 6m clear height.

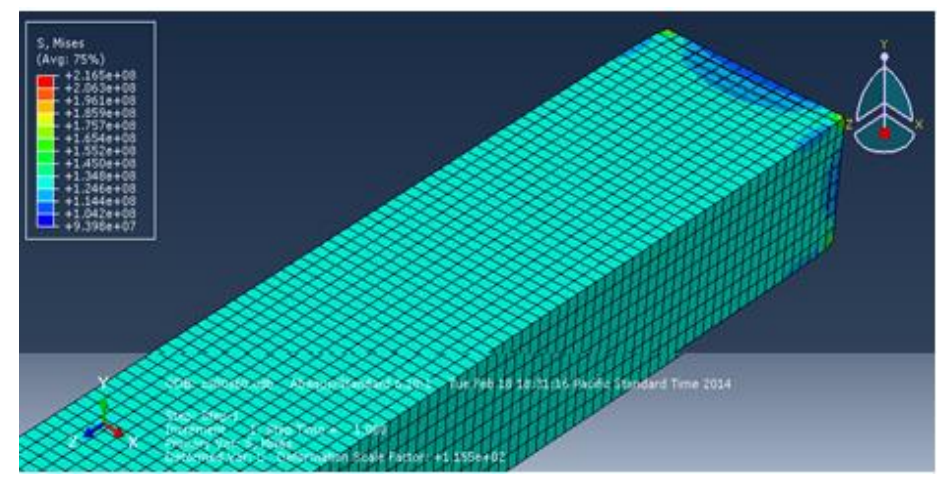

Figure 30: Slight buckling deformation at the base of the model and increase in dimension.

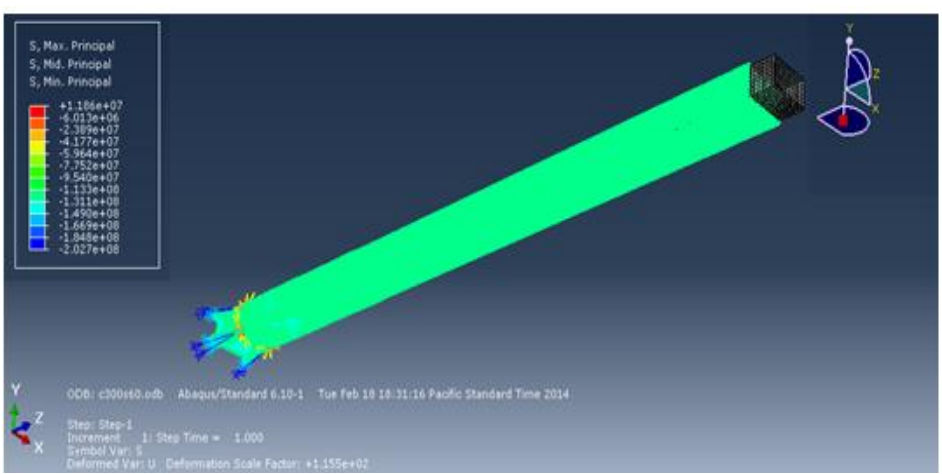

Figure 31: Contour deformation spectrum depicting column shortening and deformation at the base of the column after applying $1.3 \mathrm{e} 8 \mathrm{kN} / \mathrm{m}^{2}$ of pressure.

\subsection{Comparison}

Steel exhibits more deformation for longer hollow sections in response to axial compressive loads compared to CFRP. The analysis and results above highlight the effect of length on the failure of CFRP hollow sections under compressive load. CFRP is generally poor in compression in comparison to its tensile capacity but at critical buckling loads hollow columns will shorten and increase in lateral dimension as a result of shortening but there is no case of buckling at mid-height and even high levels of deformation at the base. Instances where CFRP is, as confinement, increase in lateral dimension is a reason for debonding and delamination which applies mostly for reinforced concrete columns.

\subsection{Material Thickness}

A comparison between CFRP and steel hollow sections with respect to material thickness, models of the same clear height and sectional size for CFRP and steel are tested with ABAQUS/CAE and simulated results are used to analyze the comparative safety of both materials under axial compressive loads. Figures 32 to 37 indicate the behaviour of CFRP for the material thicknesses employed in the evaluation, whiles Figures 38 to 43 show that of steel and its 
corresponding material thickness for the hollow sections investigated.

C80 x 60 (CFRP) 5mm thick, 3m

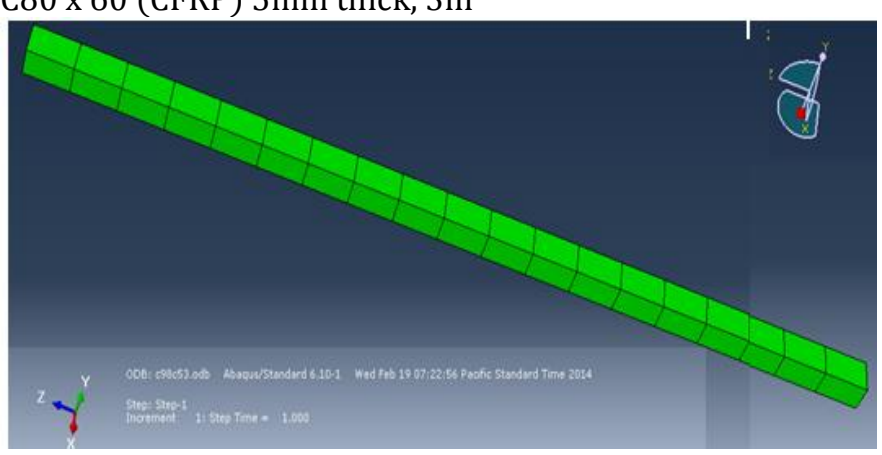

Figure 32: Undeformed plot of $680 \times 60$ (CFRP) rectangular sizes with larger mesh sizes.

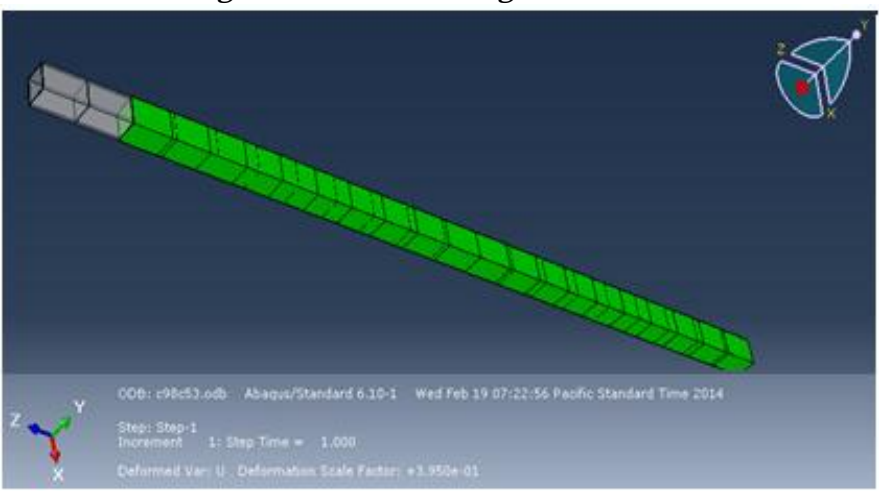

Figure 33: Superimposed CFRP column with fold along its length and shortening of column.

C80 x 60 (CFRP) $10 \mathrm{~mm}$ thickness

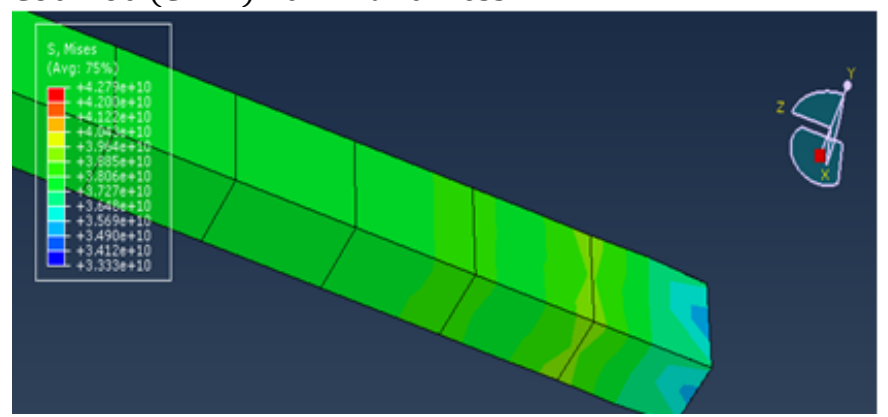

Figure 34: Buckling and increase in lateral dimension at base of column with deformation contour depicting region of deformation after applying $1.8 e 8 \mathrm{kN} / \mathrm{m}^{2}$ with deformation scale factor of $+3.9 e-01$.
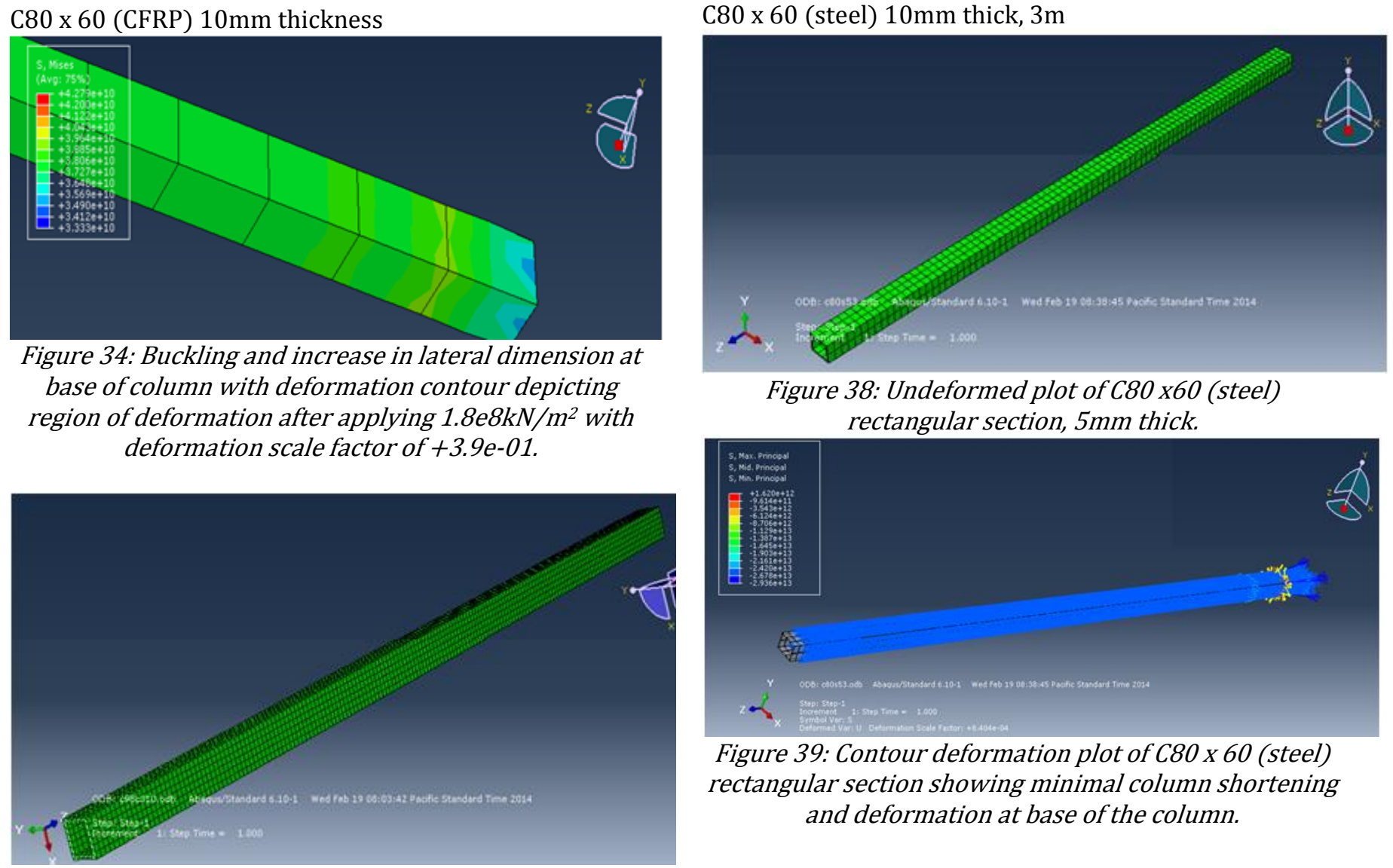

Figure 37: Slight deformation at the base of the rectangular hollow section with deformation scale factor of $3.95 \mathrm{e}=1$ after applying pressure of $3.8 \mathrm{e} 8 \mathrm{kN} / \mathrm{m}^{2}$.

C80 x 60 (steel) $10 \mathrm{~mm}$ thick, 3m

Figure 36: Deformed plot of $680 \times 60$ (CFRP) with

superposition showing column shortening

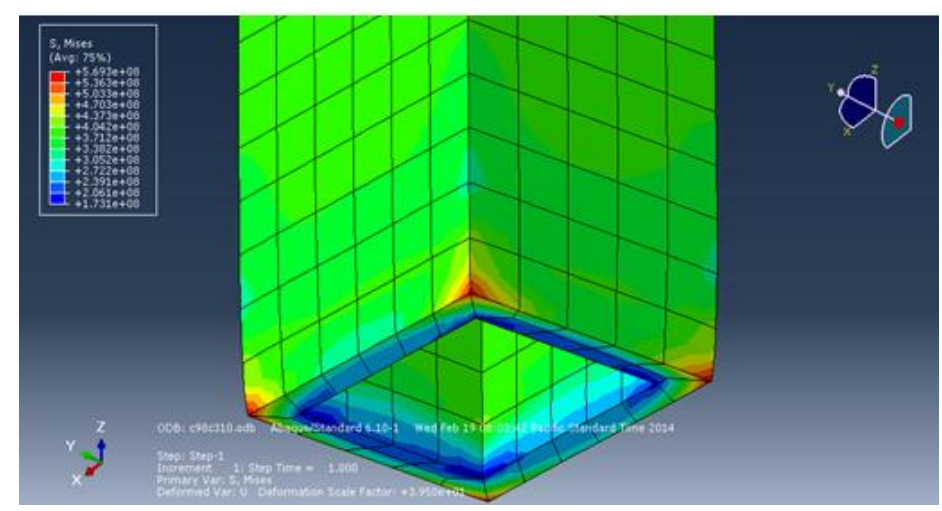

Figure 38: Undeformed plot of C80 x60 (steel) rectangular section, $5 \mathrm{~mm}$ thick.

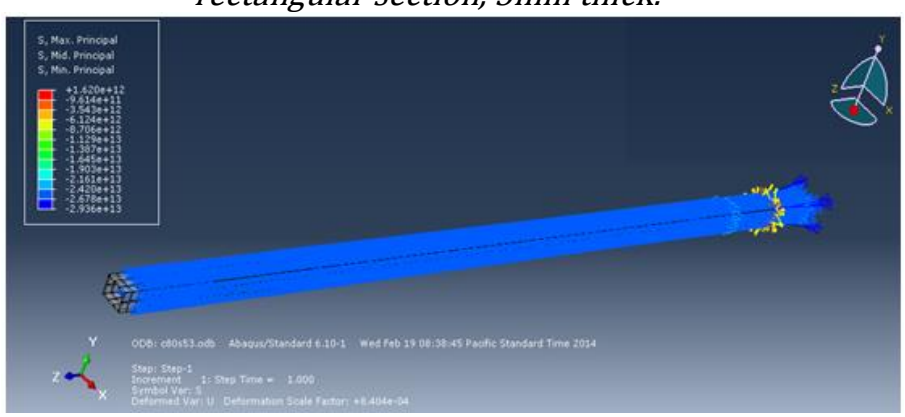

Figure 39: Contour deformation plot of C80 x 60 (steel) rectangular section showing minimal column shortening and deformation at base of the column.

Figure 35: Undeformed plot of $690 \times 60$ (CFRP) rectangular hollow section $10 \mathrm{~mm}$ thick 


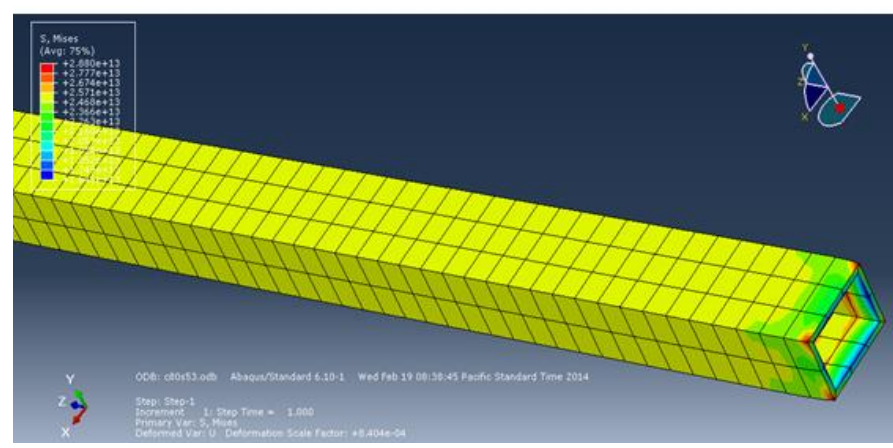

Figure 40: Slight deformation at the base of the rectangular hollow section with deformation scale factor of $+8.4004 \mathrm{e}-04$ after applying pressure of $2.5 \mathrm{e} 8 \mathrm{kN} / \mathrm{m}^{2}$

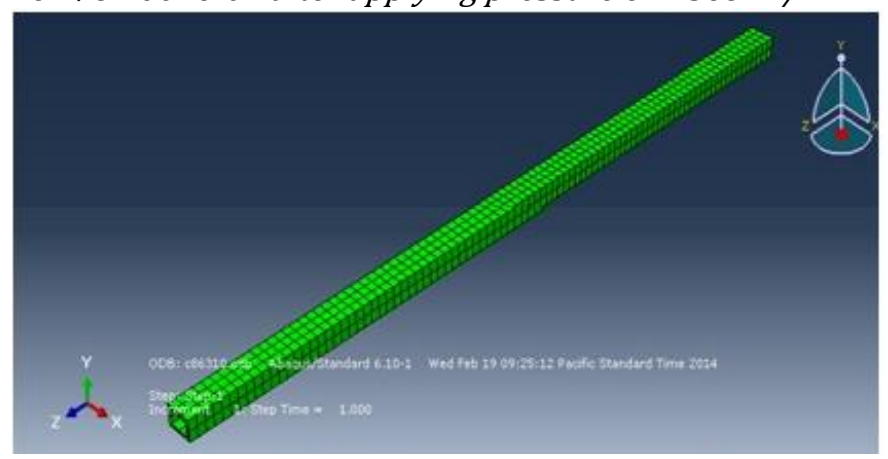

Figure 41: Undeformed plot of C80 x60 (steel rectangular hollow section, $5 \mathrm{~mm}$ thick.

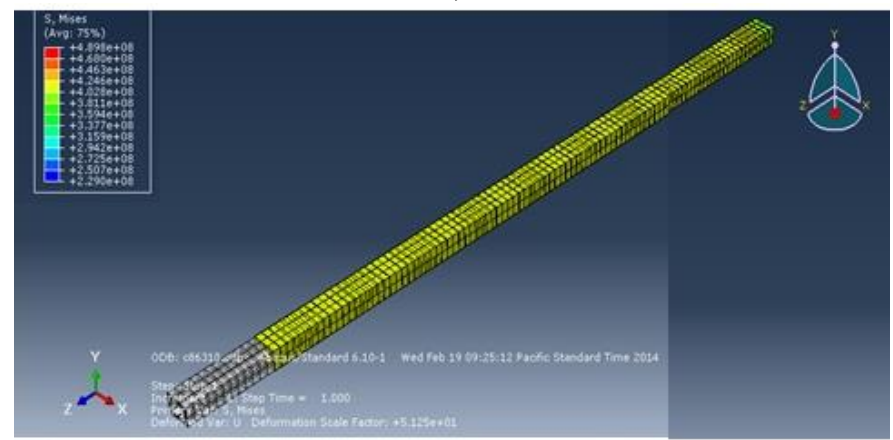

Figure 42: Superimposed steel hollow section showing increase in lateral dimension and deformation at the base of the column.

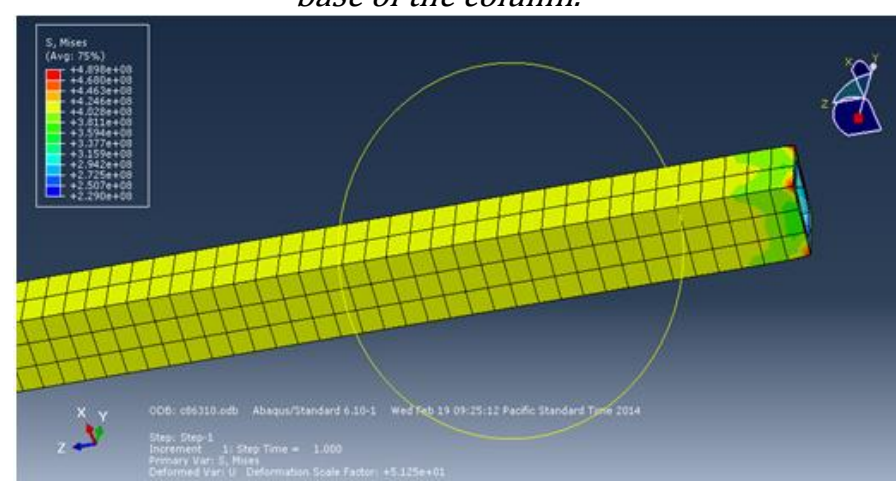

Figure 43: Slight deformation at the base of the rectangular hollow section with deformation Scale factor of $+5.125 e+01$ after applying pressure of $4.1 \mathrm{e} 8 \mathrm{kN} / \mathrm{m}^{2}$

\subsection{Comparison}

At $5 \mathrm{~mm}$ thickness CFRP buckles at the base of the column and folds along its length as a result of column shortening and at $10 \mathrm{~mm}$ thickness column shortening is minimal even though there is a slight deformation at the base of the column. For steel, there is considerable deformation and column shortening for both $5 \mathrm{~mm}$ and $10 \mathrm{~mm}$ thickness of steel material under axial load. The deformation scale factor range of $+8.404 \mathrm{e}-04$ $(5 \mathrm{~mm})$ and $+5.125 \mathrm{e}+0(10 \mathrm{~mm})$ for steel shows that there's a considerable effect of material thickness on the deformation and failure of hollow steel columns. Deformation scale factor range for CFRP +3.950e$01(5 \mathrm{~mm})$ and $+3.950 \mathrm{e}+1(10 \mathrm{~mm})$ shows that there's a less considerable effect of material thickness for CFRP hollow section under compressive axial loads and thus stands out for structural safety can be confidently used in place of steel.

This infers that CFRP, notwithstanding its poor compressive properties, will deform way less than steel under pure compressive axial loads and proves the safety of CFRP hollow sections with respect of material thickness.

No CFRP hollow section buckled at mid-height at critical buckling load and shows how stiff CFRP is under compressive loads even if the above factors show that there are instances where small sectional deformations can occur. ABAQUS/CAE provide field output results for all tested models.

\section{CONCLUSION}

The summary of this study on the safety of CFRP hollow sections in compression is as follows:

(i) The safety of Carbon Fibre Reinforced Plastic (CFRP) hollow sections can be assessed on the basis of how they deform under compressive loads relative to how steel deforms under the same loading conditions. Outputs from ABAQUS/CAE finite element software show that CFRP will deform less relative to steel at the same sectional size and thickness. CFRP and steel hollow sections will shorten in length under the influence of critical buckling load.

(ii) Rectangular CFRP hollow sections of nearly equal or equal sectional area of CFRP circular hollow section at the same height and material thickness will deform less under critical compressive loads; hence rectangular sections are more resistant to compressive loads and will be safer in large load situations such as bridge deck, and large tanking facilities.

(iii) The investigation shows that sectional size has a minimal effect on the deformation of CFRP hollow sections in compression and CFRP offers an option of substituting structural elements of different 
sizes over well considered instances to carry compressive loads and still offering an appreciable structural safety level.

(iv) The finite element modeling of hollow columns using ABAQUS/CAE indicates that there is no higher strength for the shorter columns with larger sectional area over slender columns with smaller sectional areas for CFRP hollow sections, which might be due to the assumptions of consistent and uniform material in the models, the assumption of perfect verticality, perfect fixity assumption at the base of columns and etcetera.

(v) The effect of variation in material thickness in relation to deformation of hollow sections in compression is more pronounced in steel and minimal in CFRP, which explains how structurally safe CFRP hollow sections are under compressive loads and its advantage over steel.

(vi)CFRP hollow sections shorten under critical compressive loads hence CFRP hollow sections are much more effective when used as beams and when sections are not hollow.

\section{REFERENCES}

[1] Abdelkarim, O. I., Gheni, A., Anumolu, S. and Wang, Song. "Hollow-Core FRP-Concrete-Steel Bridge Columns under Extreme Loading", Missouri Department of Transportation, Research, Development and Technology, Missouri University of Science and Technology, Rolla, Missouri. http://ntl.bts.gov/lib/55000/55100/55155/cmr15008.pdf. 2015. Accessed on July, 2016.

[2] Lignola G.P., Prota A., Manfredi G. and Cosenza E.. "Experimental performance of RC Hollow Columns Confined with CFRP”. ASCE Journal of Composites for Construction, Vol. 11, February 1, 2007. pp 42-49.

[3] Modarelli, R., Micelli, and F. Manni, O. "FRPConfinement of Hollow Concrete Cylinders and Prisms". ACI SP, Vol. 230, October1, 2005, pp 10291046.

[4] Wenbin, S., Qiangqiang Z. and Weizhong H., "Experimental Study of Concrete-filled Carbon Fibre Reinforced Polymer Tube with Internal Reinforcement under Axial Loading" Materials Science, Vol 20, No 4, November 17, 2014, pp 493497.

www.matsc.ktu.lt/index.php/MatSc/article/viewFile $\measuredangle 6035 / 4372 \mathrm{~b}$.

[5] Yiyan, L., Na, L. and Shan, L., "Behaviour of FRPConfined Concrete-Filled Steel Tube Columns", Polymers, Open Access, Vol. 6, May 8, 2014, pp 13331349, www.mdpi.com/journal/polymers.
[6] Ching, A. "Behaviour of FRP-Confined Concrete", Thesis for the award of Master of Science Degree in Civil Engineering, Massachusetts Institute of Technology, web.mit.edu/.../2001_master_Behavior/ FRP-Confined/Concrete, 2001.

[7] Kiruthika, P., Balasubramanian, S., Sundarraja, M. C. and Jegan, J., "Strengthening of Cncrete Filled Steel Tubular Columns using FRP Composites", International Journal of Innovative Research in Science, Engineering and Technology, Vol. 4, April 2015, pp 2250-2259.

[8] Schnerch, D., Standford, K., Sumner, E. and Rizkalla, S., "Bond Behavior of CFRP Strengthened Steel Bridges and Structures", Proceedings International the International Symposium on Bond Behaviour of FRP in Structures, International Institute for FRP in Construction. Hong Kong, China, Dec. 7-9, 2005, pp. 435-443.

[9] Liu, H. B., Zhao, X. L. and Al-Mahaidi, R., "Effect of Fatigue Loading on Bond Strength of CFRP Bonded Steel Plate Joints", Proceedings International the International Symposium on Bond Behaviour of FRP in Structures, International Institute for FRP in Construction. Hong Kong, China, Dec. 7-9, 2005, pp. 451-456.

[10] Al-Mosawe, A. and Al-Mahaidi, R, "Bond Characteristics between Steel and CFRP Laminate under Impact Loads", 23rd Australasian Conference on the Mechanics of Structures and Materials (ACMSM23), 2014.

[11] Quayyum, S. "Bond behaviour of Fibre Reinforced Polymer (FRP) Rebars in Concrete", M. Sc. Thesis, The University of British Columbia, Okanagan, 2010.

[12] Abeygunasekara, S. and Amarasinghe, T. I. "Evaluation Of CFRP/Steel Bond Performance under Tropical Environmental Condition in Sri Lanka", SAITM Research Symposium on Engineering Advancements 2014 (SAITM - RSEA 2014)

[13] Fawzia, S. and Karim, M. A. (2009) "Investigation into the Bond between CFRP and Steel Plates" World Academy of Science, Engineering and Technology 53 2009 pp 321-325.

[14] Shahanara, K. "Bond Strength of Steel Hollow Sections using Carbon Fibre Reinforced Polymer Composites", M. Sc. Thesis, Queensland University of Technology., 2013.

[15] Cromwell, J. R., Harries, K. A. and Shahrooz, B. M. "Environmental Durability of Externally

Bonded FRP Materials Intended for Repair of Concrete Structures", Construction and Building Materials, May 25, 201, pp 2528-2539.

[16] Fawzia, S and Kabir, M. H., "A Review on Environmental Durability of CFRP

Vol. 35, No. 4, October, 2016 
Strengthened System", Australian Structural Engineering Conference, Engineers Australia, Perth, WA, 2012 pp 1-8. http://eprints.qut.edu.au/57405.

[17] Sundarraja, M. C. and Shanmugavalli, B. "Experimental Investigation on the Behaviour CHS Short Columns Strengthened Using FRP Composites under Compression", International Journal of Advanced Structures and Geotechnical Engineering, Vol. 3, April 2014, pp 91-97.

[18] Mirmiran, A., Shahawy, M., Samaan, M., Echary, H. E.,Mastrapa, J. C., and Pico, O."Effect of Column Parameters on FRP-Confined Concrete." Journal of Composites for Construction, Vol. 2, 1998, pp.175185.

[19] Mirmiran, A.and Shahawy, M. "Behaviour of Concrete Columns Confined by Fibre Composites", Journal of Structural Engineering, ASCE, Vol. 123(5), 1997, pp 583-590.

[20] Nanni, A. and Bradford, N. M. "FRP Jacketed Concrete under Uniaxial Compression", Construction and Building Materials, Vol. 9(2), 1995, pp 115-124.
[21] Picher, F., Rochette, P. and Labossiere, P. "Confinement of Concrete Cylinders with CFRP", 1st International Conference on Composite Infrastructures. Tucson, Arizona, USA, 1996, pp 829841.

[22] ACI Committee 318. "Building Code Requirements for Structural Concrete (318-02) and Commentary (318R-02)," American Concrete Institute, Farmington Hills, Michigan, 2002.

[23] CAN/CSA-S16-09 "Design of Steel Structures", wWw.cisc-icca.ca/solutions-centre. Published: $06 / 01 / 2014$

[24] Mosley, B., Bungey, J. and Hulse, R. "Reinforced Concrete Design", BookPower, Great Britain, 2007.

[25] Eurocode 2: "Design of concrete structures" - Part 11: General rules and rules for Buildings, 2004

[26] British Standards Institution, BS 5950 Structural use of steelwork in building", London, BSI., 1990. 